Article

\title{
Decarbonization of the Iron and Steel Industry with Direct Reduction of Iron Ore with Green Hydrogen
}

\author{
Abhinav Bhaskar *,+ (D), Mohsen Assadi (1) and Homam Nikpey Somehsaraei (1) \\ University of Stavanger, Faculty of Science and Technology, Instiute of Energy and Petroleum Engineering, \\ 4036 Stavanger, Norway; mohsen.assadi@uis.no (M.A.); homam.nikpey@uis.no (H.N.S.) \\ * Correspondence: abhinav.bhaskar@uis.no \\ + Current address: University of Stavanger, 4036 Stavanger, Norway.
}

Received:11 December 2019; Accepted: 3 February 2020; Published: 9 February 2020

\begin{abstract}
Production of iron and steel releases seven percent of the global greenhouse gas (GHG) emissions. Incremental changes in present primary steel production technologies would not be sufficient to meet the emission reduction targets. Replacing coke, used in the blast furnaces as a reducing agent, with hydrogen produced from water electrolysis has the potential to reduce emissions from iron and steel production substantially. Mass and energy flow model based on an open-source software (Python) has been developed in this work to explore the feasibility of using hydrogen direct reduction of iron ore (HDRI) coupled with electric arc furnace (EAF) for carbon-free steel production. Modeling results show that HDRI-EAF technology could reduce specific emissions from steel production in the EU by more than $35 \%$, at present grid emission levels $\left(295 \mathrm{kgCO}_{2} / \mathrm{MWh}\right)$. The energy consumption for 1 ton of liquid steel (tls) production through the HDRI-EAF route was found to be $3.72 \mathrm{MWh}$, which is slightly more than the $3.48 \mathrm{MWh}$ required for steel production through the blast furnace (BF) basic oxygen furnace route (BOF). Pellet making and steel finishing processes have not been considered. Sensitivity analysis revealed that electrolyzer efficiency is the most important factor affecting the system energy consumption, while the grid emission factor is strongly correlated with the overall system emissions.
\end{abstract}

Keywords: hydrogen; direct reduction of iron ore; green steel production; industrial decarbonization

\section{Introduction}

Anthropogenic climate change is one of society's greatest challenges. Decarbonization of all sectors of the energy system is essential to mitigate climate change. Although the industrial sector consumes one-third of the primary energy resources and releases one-quarter of the energy-related greenhouse gas emissions, it has not received as much attention from researchers and policy-makers as other demand sectors like electricity generation, buildings and transport etc. The non-homogeneity of industrial plants and the use of fossil fuels as feedstock makes it difficult to find effective strategies to decarbonize industries. Iron and steel, chemicals, cement, non-ferrous metals, paper, and pulp etc. are referred to as energy-intensive industries (EII) because they use energy resources as primary raw material. Energy efficiency has played a major role in reducing the industrial sector's energy intensity and emissions. Nonetheless, incremental changes in current industrial production technologies would not reach the emission reduction goals needed to avoid catastrophic effects of anthropogenic climate change [1,2].

Steel is the backbone of modern civilization. It is used in buildings, transport, packaging, shipping and infrastructure etc. Approximately 1.73 billion tons of crude steel was produced in 2017 [3]. The apparent steel use per capita (finished steel products) was $216.3 \mathrm{~kg}$ in 2017. Industrialized countries like Germany have a high apparent steel use per capita of approximately $500 \mathrm{~kg}$. India, a developing 
country, on the other hand, has a per capita steel consumption of $66.3 \mathrm{~kg}$. As the standard of living in developing countries increases, demand for steel will grow further. The demand for steel will increase until 2050 [4]. Steel could be produced by reducing iron ore or by recycling steel scrap in an electric arc furnace (EAF). Iron and steel sector releases seven percent of the total $\mathrm{CO}_{2}$ emission and $16 \%$ of the total industrial emission of $\mathrm{CO}_{2}$ globally [5,6]. Limited availability of scrap and demand for special grades of steel, which can not be produced from steel recycling, would lead to an increased demand for ore based steel production in the future. More than $80 \%$ [3] of the ore based steel is produced through the BF-BOF route. The BF-BOF route uses approximately $18 \mathrm{GJ} / \mathrm{t}$ of energy supplied from coal [7], and has an emission intensity of approximately $1870 \mathrm{kgCO}_{2} / \mathrm{tls}[4,8]$ (considering pellet making, steel rolling and finishing steps). Majority of the emissions is released from the blast furnace (61\%) and coke making plant (27\%) [9].

Some of the alternative processes with significantly reduced carbon footprint are BF-BOF with carbon capture and storage (CCS), direct reduction of iron ore (DRI) with CCS, electrowining (electrolysis of iron ore) [10] and green hydrogen-based DRI production. Integration of CCS in steelmaking processes is being explored under the ultra-Low carbon dioxide $\left(\mathrm{CO}_{2}\right)$ steelmaking (ULCOS) [11,12] project. However, concerns over the safe transport and storage of captured makes CCS options less attractive. Electrowining or molten electrolysis of iron ore is a relatively new technology and is quite far from reaching commercial feasibility. Hydrogen direct reduction of iron ore (HDRI)-EAF based steel production is the most viable alternative to BF-BOF based steel production, as the production of hydrogen with intermittent renewable energy generators has an additional benefit of providing flexibility to the electricity grid [7]. Hydrogen, as an energy carrier, has applications in other sectors of the energy system, like chemical production, heavy transport, aviation, shipping etc. Large scale production, storage and transport of hydrogen to cater to the demands of the steel industry will reduce the price of hydrogen for other industries like chemical production, transportation, buildings and district heating etc. [13-15]. The use of green hydrogen in the iron and steel sector, has the potential to reduce emissions by 2.3 gigatonnes of carbon dioxide per year $\left(\mathrm{GtCO}_{2} / \mathrm{y}\right)$ [16] globally.

The first HDRI based steel production unit was commissioned in the year 1999 in Trinidad. Production was based on fluidized bed reactors [17]. The plant produced steel with $95 \%$ metallization rate, at a production capacity of 65 tonnes of liquid steel per hour (tls/hr) [18]. Energiron, which is a commercial supplier of natural gas-based DRI shaft furnaces, tested direct reduction of iron ore with more than 90\% hydrogen in its test facility at Hysla, Monterrey [19].The pilot plant had a capacity of 36 tls/day of hot and cold DRI production. A high metallization rate of $94-96 \%$ was achieved. The company claims that their shaft furnace reactors could be easily optimized to use $100 \%$ hydrogen for the reduction of iron ore. It is supplying shaft furnace reactors to many European demonstration projects for hydrogen-based steel production. The higher cost of hydrogen compared to fossil fuel resources is a roadblock for further development of the technology. There is a renewed interest in the hydrogen economy among researchers, policy-makers and industries, on the back of declining prices of renewable electricity generators and demand for more flexibility in the electricity grid to integrate intermittent renewable energy generators [16]. Techno-economic modeling of hydrogen and ammonia production using water electrolysis was carried out by [20]. They found that the cost of green hydrogen could reduce to $2 \mathrm{USD} / \mathrm{Kg}$, which is comparable to hydrogen produced from fossil fuel sources. Researchers at the Technical University of Munich and Stanford University found that the cost of hydrogen produced from renewable electricity has decreased to $€ 3.23 \mathrm{~kg}^{-1}$ and will further decrease to $€ 2.50 \mathrm{~kg}^{-1}$ in Germany and Texas [21] within the next decade. The cost of producing hydrogen from renewable electricity could fall $30 \%$ by 2030 as a result of declining costs of renewable energy and the scaling up of hydrogen production [22]. In the HYBRIT project [23], hydrogen-based steel production would be demonstrated by Luossavaara-Kiirunavaara Aktiebolag (LKAB), Svenskt Stål AB (SSAB), Vattenfall along with Swedish energy agency. Voestalpine is testing a six-megawatt proton exchange membrane electrolyzer (PEM) developed by Siemens for hydrogen production [24]. Under the Salcos [25] project along with GrInHy2 [26] and Windh2 [27], the feasibility of integrating 
$30 \mathrm{MW}$ of wind electricity generators with solid oxide electrolyzers for hydrogen production at a steel production facility in Germany is being explored. Tata steel Europe, Nouryon and the port of Amsterdam have partnered to develop the largest green hydrogen cluster in Europe [28]. Arcelormittal is building a demonstration HDRI unit, with a production capacity of 100,000 $t$ /year [29]. The plant will use grey hydrogen produced from natural gas until green hydrogen becomes cost-competitive. Midrex technologies will supply the shaft furnace reactor for the plant [30]. Thyssenkrupp has begun testing of hydrogen-based steel production at its production facility in Duisburg, Germany. Coke has been replaced with hydrogen in one of the nine blast furnaces. If the results from the pilot study are favorable, hydrogen could replace coke in all blast furnaces [31].

There have been many discussions about the use of $100 \%$ hydrogen as reducing agent DRI based steel production $[7,9,32-35]$ in the scientific literature. However, energy consumption and emissions values reported in the literature vary significantly. There is a lack of clarity about system configuration and boundaries. In this work, system boundary has been clearly defined, making it easier to compare the energy and emission intensity of BF-BOF and HDRI-EAF based steelmaking process. More details about the process parameters are included in this model than other comparable models available in the literature. The model codes are written in an open-source software and are available to the scrutiny of other researchers [36]. Theoretical concepts and the chemical reactions, along with discussions on the reaction kinetics are presented in Section 2. The HDRI-EAF model, along with mass and energy flows through the different components are discussed in Section 3. Modelling results are presented in the Section 4, followed by the conclusions in Section 5 and discussions on future work in Section 6.

\section{Concept}

Direct reduction of iron ore refers to the conversion of solid iron ore to metallic iron without conversion to the liquid phase [37]. Majority of the direct reduced iron (DRI) [38] is produced by reacting iron oxide with hydrocarbon-based reducing gases produced from reforming natural gas or coal gasification [39-42]. DRI technology has been deployed commercially and five percent of the total global steel is produced through the DRI route [43]. Lower capital investment, space requirements, and simpler design and operation make it easier to build and operate a DRI plant [33]. With the declining price of shale gas, there has been an upsurge in the installation of DRI plants in the US [44]. Shaft furnaces, rotary kilns, rotary hearth furnaces and fluidized bed reactors are used for direct reduction of iron ore. Most of the DRI plants use shaft furnace reactors developed by MIDREX [43] and HYL-Energiron [45] technologies. Shaft furnaces are moving bed counter-current reactors. Rotary hearth furnaces are used, when coal is used as the source for production of reducing gases [33]. Kinetic studies have revealed that the reduction of hematite occurs in stages, it is first converted to magnetite and at temperatures above $570{ }^{\circ} \mathrm{C}$, wustite is formed [46]. At temperatures below $570{ }^{\circ} \mathrm{C}$, magnetite is converted to iron directly [35] as wustite is not stable below $570{ }^{\circ} \mathrm{C}$. Reduction reactions occurring inside the shaft furnace, with syngas as the reducing gas are depicted in Equations (1) and (2). Exothermic reduction of Hematite by CO [42,47]:

$$
\mathrm{Fe}_{2} \mathrm{O}_{3}(\mathrm{~s})+3 \mathrm{CO}(\mathrm{g}) \longrightarrow 2 \mathrm{Fe}(\mathrm{s})+3 \mathrm{CO}_{2}(\mathrm{~g})
$$

Endothermic reduction of Hematite by $\mathrm{H}_{2}$ :

$$
\mathrm{Fe}_{2} \mathrm{O}_{3}(\mathrm{~s})+3 \mathrm{H}_{2}(\mathrm{~g}) \longrightarrow 2 \mathrm{Fe}(\mathrm{s})+3 \mathrm{H}_{2} \mathrm{O}(\mathrm{g}) .
$$

Natural gas is converted to a mixture of $\mathrm{CO}$ and $\mathrm{H}_{2}$ using steam methane reforming (SMR). The reaction is endothermic and has a reaction enthalpy of $206 \mathrm{kJmol}^{-1}$ [48], as shown in Equation (3).

$$
\mathrm{CH}_{4}(\mathrm{~g})+\mathrm{H}_{2} \mathrm{O}(\mathrm{g}) \longrightarrow \mathrm{CO}(\mathrm{g})+3 \mathrm{H}_{2}(\mathrm{~g}) \text {. }
$$


Countries with large reserves of natural gas such as Saudi Arabia, Qatar, USA(shale gas) and Iran have deployed the technology for steel production [43]. The DRI produced from the shaft furnace can either be fed to an EAF as hot DRI or cooled and briquetted for transport. Addition of DRI in the EAF reduces the dependence on scrap and improves the quality of the steel produced [49-51].

\section{Hydrogen Direct Reduction of Iron Ore}

In the HDRI-EAF system, hydrogen is used as the reducing gas in a moving bed shaft furnace. The DRI is fed to an EAF for steel production. The reduction reactions are depicted in Equations (4)-(6) [52]. The reduction reaction is endothermic and energy in the form of heat needs to be supplied to carry the reaction forward [37]. The reaction propagation and the different processes involved in the reaction are depicted in Figure 1.

$$
\begin{gathered}
3 \mathrm{Fe}_{2} \mathrm{O}_{3}(\mathrm{~s})+\mathrm{H}_{2}(\mathrm{~g}) \longrightarrow 2 \mathrm{Fe}_{3} \mathrm{O}_{4}(\mathrm{~s})+\mathrm{H}_{2} \mathrm{O}(\mathrm{g}) \\
(1-\mathrm{x}) \mathrm{Fe}_{3} \mathrm{O}_{4}(\mathrm{~s})+(1-4 \mathrm{x}) \mathrm{H}_{2}(\mathrm{~g}) \longrightarrow 3 \mathrm{Fe}_{1-\mathrm{x}} \mathrm{O}(\mathrm{s})+(1-4 \mathrm{x}) \mathrm{H}_{2} \mathrm{O}(\mathrm{g}) \\
\mathrm{Fe}_{1-x} \mathrm{O}(\mathrm{s})+\mathrm{H}_{2}(\mathrm{~g}) \longrightarrow(1-\mathrm{x}) \mathrm{Fe}(\mathrm{s})+\mathrm{H}_{2} \mathrm{O}(\mathrm{g})
\end{gathered}
$$

As depicted in Figure 1, the chemical reaction occurs by adsorption of hydrogen gas on the iron oxide interface. At high temperatures, the rate of chemical reaction is higher than the transport rate or mass transfer rate of reactants and products. This observation is in accordance with the Arrhenius equation [37]. In a solid-gas reaction at high temperatures, diffusion of reactants and products is often the rate-limiting step. The porosity of the pellets is an important factor, as higher porosity of the raw material leads to higher permeability and diffusivity of the reactants and products. The size and geometry of the pellets and temperature of the inlet gas have a strong influence on the reaction rate. The reaction rate varies inversely with the size of the pellets [53]. The reaction rate is faster with hematite ore than magnetite ore as the porosity of intermediate reaction products formed by hematite is higher [54]. Addition of biomass in the iron ore pellets could increase the porosity of the pellets and reduce the apparent activation energy required for the reduction reaction [55]. Water vapor formed during the reduction of iron oxide has a lower adsorption and desorption rate than hydrogen. At lower temperatures, this could affect the rate of reaction. Experimental studies have shown that the rate of iron ore reduction reaction is higher with pure hydrogen than with traditionally used syngas (mixture of $\mathrm{CO}$ and $\mathrm{H}_{2}$ ) [56] between $700-900{ }^{\circ} \mathrm{C}$. Higher reduction rates could lead to a more compact design of the shaft furnace for the same DRI output, which could reduce capital costs and lower the heat losses from the shaft furnace, owing to a smaller surface area available for heat transfer. The addition of small amounts of $\mathrm{CO}$ in the reducing gas mixture can slow down the reduction reaction significantly, as CO reduces the diffusivity of the reducing gases [57]. By conducting experiments on hematite reduction with hydrogen at different temperatures, it was found that at temperatures higher than $900{ }^{\circ} \mathrm{C}$, the reaction rate decreases because of sintering and formation of a dense outer layer on the iron ore pellets [46]. The values for apparent activation energy for the reduction reaction varies from $11 \mathrm{~kJ} \mathrm{~mol}^{-1}$ to $246 \mathrm{~kJ} \mathrm{~mol}^{-1}$. The large variation in the values of apparent activation energies is due to its dependence on multiple factors. Thermo-physical properties of the input material, reducing gas composition, reduction temperature, particle size and the experimental set-up are some of the variables listed by [37]. There is a need for a more thorough investigation to evaluate the apparent activation energy required for iron ore reduction reaction with pure hydrogen. 


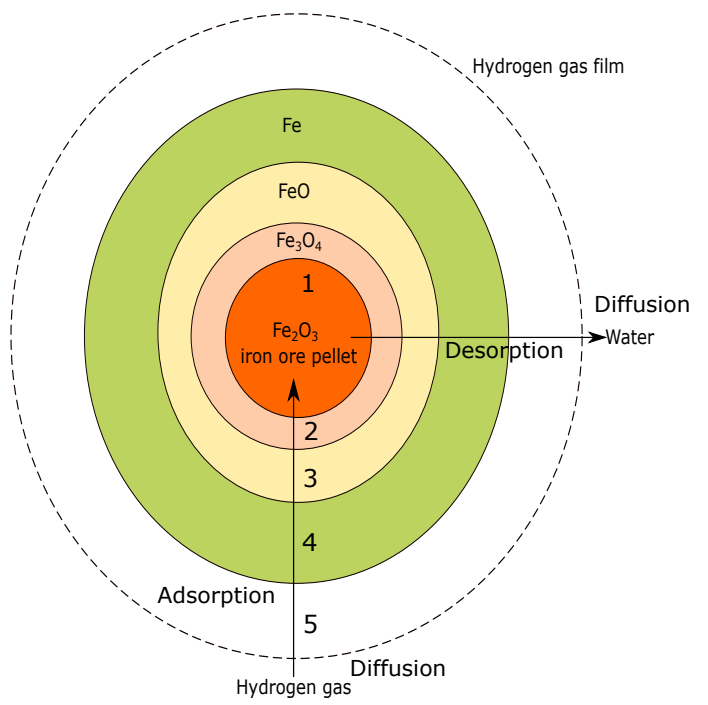

(a)

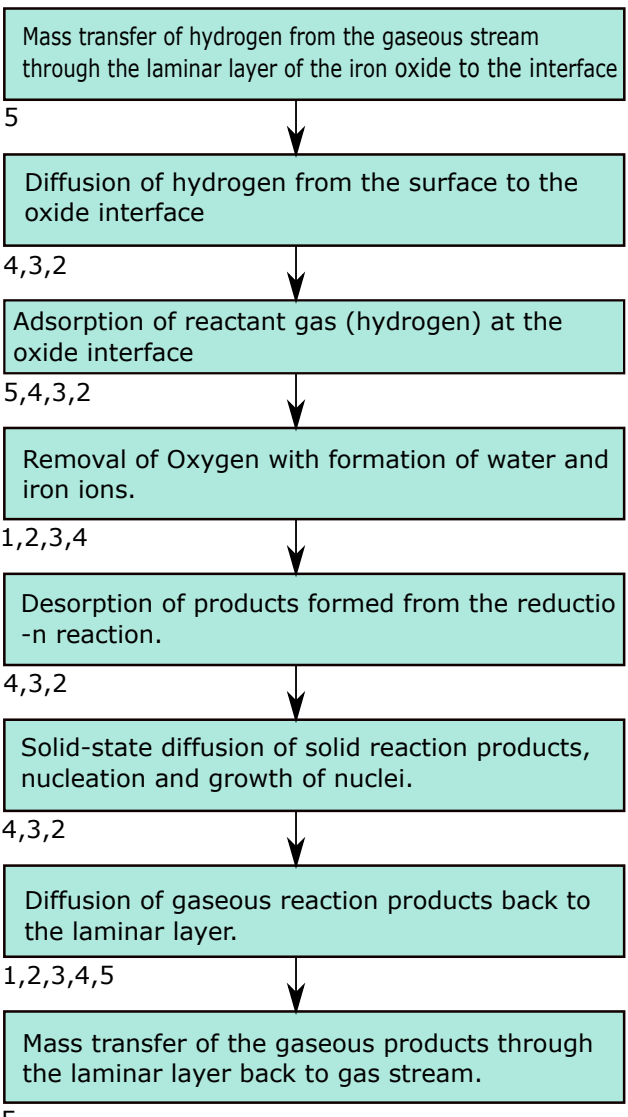

(b)

Figure 1. (a) Shrinking core model depicting the evolution of iron ore reduction reaction with hydrogen [56]. (b) Process steps in the reduction of iron ore pellets with hydrogen [37]. The location of the process steps is represented from numbers 1 to $5(1 \mathrm{~b})$, which are also depicted in the shrinking core model (1a).

\section{Methodology}

The objective of this analysis is to improve the understanding of the impact of different process parameters on the energy and emission intensity of the steel production system. A new system configuration was modeled and analyzed in this work. The system configuration is shown in Figure 2. Other configurations with different technologies for hydrogen production, pellet pre-heating, adsorption of hydrogen from the waste gas stream etc. are also possible and should be explored. Energy consumption and emissions related to iron ore mining, pellet making and downstream steel finishing steps have not been considered in this model. Modeling assumptions are presented in Appendix A. The model has been developed using Python, which is open-source software. The codes were written in the Jupyter notebook [58] environment. NumPy [47] and Pandas [59] libraries have been used for calculations and data visualization. The graphs and bar charts have been plotted using matplotlib [60] library. All these libraries could be used with the standard anaconda [61] distribution. Python codes for the model in the form of a Jupyter notebook are available for download [36]. In the following section, mass and energy flows through the different components of HDRI-EAF system will be described. 


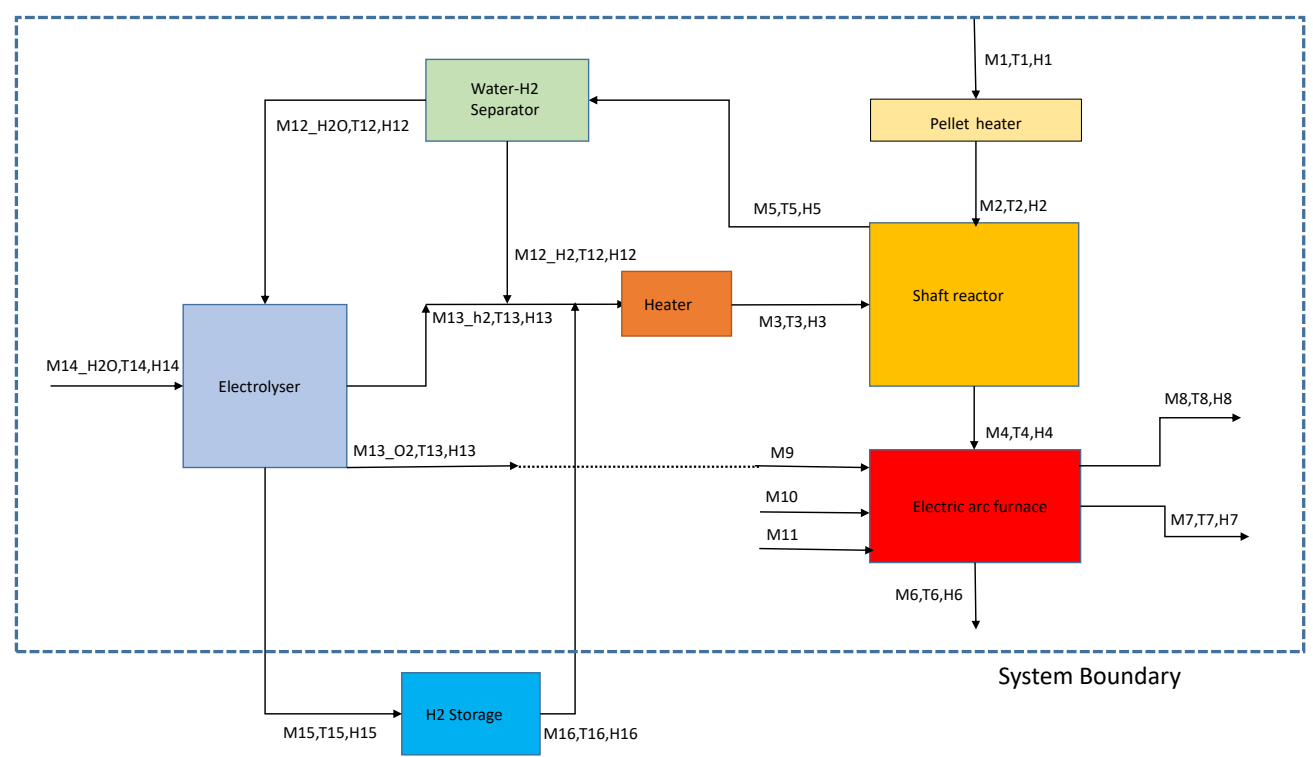

Figure 2. Schematic of the Hydrogen direct reduction shaft furnace coupled with an electric arc furnace. An electrolyzer is considered for hydrogen production.

\subsection{Pellet Heating}

It has been assumed that an electrical heating unit is used to heat iron ore pellets to $800{ }^{\circ} \mathrm{C}$. Mass and energy flow through the electrical heating unit is depicted in Figure 3. The amount of iron ore required for producing one ton of steel was calculated using Equation (7). Equations (8) and (9) describe the mass and energy flow through the pellet electrical heating system.

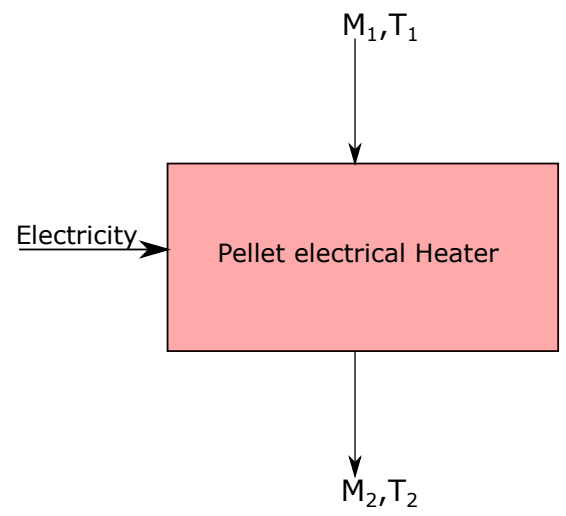

Figure 3. Mass and energy flows through the pellet heating unit.

$$
M_{1}=\frac{1}{\left(F e_{2} O_{3 \text { pure }} * F e O_{\text {ratio }}\right)}
$$

Mass balance

$$
M_{1}=M_{2}
$$

Energy balance

$$
M_{1} * h_{1}+E L_{\text {pel heater }}=M_{2} * h_{2}+\delta_{\text {heat losses }}
$$




\subsection{Direct Reduction Shaft Furnace}

The DRI shaft furnace is a counter-current solid-gas reactor, where pre-heated iron ore pellets at $800{ }^{\circ} \mathrm{C}$ are fed from the top to react with hydrogen stream entering from the bottom of the reactor. The reduction reaction is endothermic with a reaction enthalpy of $99.5 \mathrm{kJmol}^{-1}$. Iron ore particles need to be completely submerged in hydrogen for the optimal reaction rate. The ratio of actual flow rate of hydrogen to the stoichiometric flow rate of hydrogen required for the reduction reaction is represented by lambda $\lambda$ [34]. The stoichiometric flow rate of hydrogen per ton of liquid steel is calculated by Equation (10). Actual mass flow of hydrogen in the reactor is the product of $\lambda$ and stoichiometric quantity of hydrogen required to reduce 1 ton of hematite ore, as depicted in Equation (11). The mass and energy flow through the reactor are shown in Figure 4.

$$
\begin{gathered}
M_{H_{2}}=\frac{H_{2_{\text {per mole }}} * H_{2_{\text {molecular weight }}} * 10^{3}}{F e_{\text {molecular weight }}} \\
M_{3}=\lambda * M_{\mathrm{H}_{2}} .
\end{gathered}
$$

Metalization rate $(\alpha)$, is defined as the percentage of metallic iron $(\mathrm{Fe})$ leaving the shaft furnace in the iron stream. DRI contains metallic iron along with $\mathrm{FeO}$ (wustite), which needs to be reduced inside the EAF. Metalization rate of $94 \%$ has been assumed for the base case. The amount of $\mathrm{Fe}$, and $\mathrm{FeO}$ (Wustite) in the stream exiting the shaft furnace is calculated by using Equations (12) and (13). The mass balance of the shaft furnace is represented by Equation (16).

$$
\begin{gathered}
M_{4_{F e O}}=M_{1} * F e_{2} O_{3_{\text {pure }}} * F e O_{\text {ratio }} *(1-\alpha) \\
M_{4_{F e}}=1000-M_{4_{F e O}} \\
M_{4_{i m}}=M_{1}-\left(M_{4_{F e O}}+M_{4_{F e}}\right) .
\end{gathered}
$$

It is assumed that the waste gas stream is a mixture of unreacted hydrogen and water/steam produced from the reduction reaction as shown in Equation (15). The amount of water produced depends on the metallization rate. For ease of calculations, it is assumed that metallization is complete. The amount of unused hydrogen in the waste stream depends on the amount of hydrogen entering the shaft furnace. A thorough understanding of the kinetics of the reaction and design of the shaft furnace is required to calculate the exact composition and temperature of the waste gas stream. Typically, the exhaust gases in a DRI shaft furnace exit the furnace at a temperature of $275^{\circ} \mathrm{C}$ to $400{ }^{\circ} \mathrm{C}$ [42]. An exhaust gas temperature of $250^{\circ} \mathrm{C}$ has been considered in the model to account for the endothermic reaction between hydrogen and iron ore.

$$
M_{5}=M_{5_{\mathrm{H}_{2}}}+M_{5_{\mathrm{H}_{2} \mathrm{O}}}
$$

More energy is required for $100 \%$ hydrogen-based DRI production compared to reduction with syngas, as hydrogen reduction of iron ore is an endothermic reaction, whereas, reduction of iron ore with $\mathrm{CO}$ is an exothermic reaction. Energy in the form of heat is lost to the environment due to heat transfer from the shaft furnace walls. The energy flows through the reactor represented by Equation (17). 


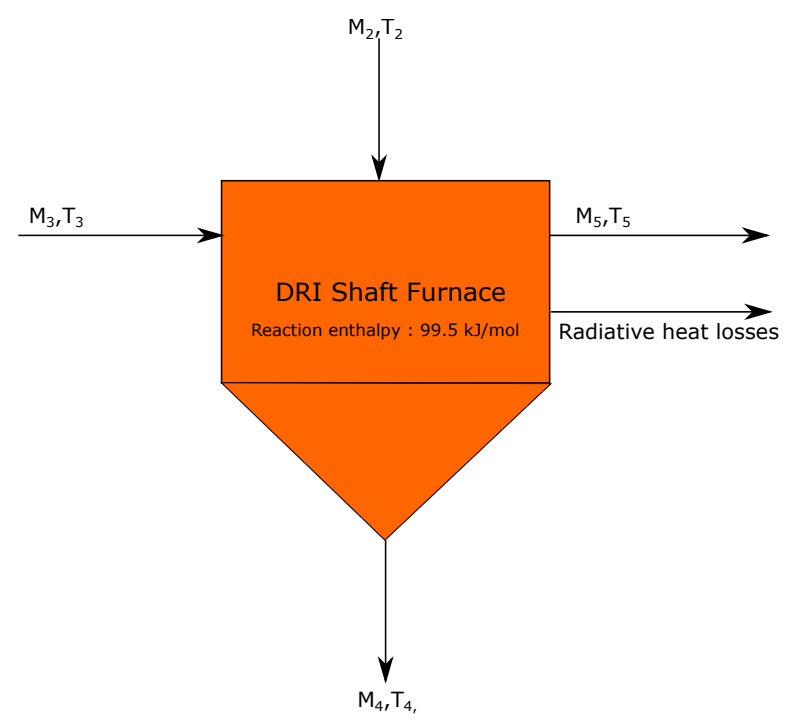

Figure 4. Mass and energy flow through the DRI shaft furnace.

Mass balance

$$
M_{3}+M_{2}=M_{4}+M_{5}
$$

Energy balance

$$
M_{2} * h_{2}+M_{3} * h_{3}=M_{4} * h_{4}+M_{5} * h_{5}+H_{\text {reaction }}+\delta_{\text {heat losses }} .
$$

\subsection{Electric Arc Furnace}

It is assumed that DRI with a metallic content of $94 \%$ enters the EAF at a temperature of $700{ }^{\circ} \mathrm{C}$. The EAF is operated with $100 \%$ hot DRI. EAF temperature is assumed to be $1650{ }^{\circ} \mathrm{C}$ to ensure complete melting of metallic iron. The efficiency of the electric arc furnace, $\beta_{e l}$, is assumed to be 0.6 to account for losses in the transformer, rectifier, electrodes and other sub-systems [51]. Carbon is added in the EAF for $\mathrm{CO}$ production. Oxygen, produced in the water electrolyzer could be added in the EAF for the production of $\mathrm{CO}$ to reduce the $\mathrm{FeO}$ in the EAF. It is assumed that $70 \%$ of the FeO entering the EAF is reduced and the rest is removed as slag. The dissolution of carbon in molten metal is an endothermic reaction and $3.59 \mathrm{KWh} / \mathrm{kg}$ of energy is used in the process. Exhaust gas stream from the EAF is assumed to be a mixture of $\mathrm{CO}$ and $\mathrm{CO}_{2}$. Additional elements are added in the molten iron to improve its thermo-physical properties. They have not been considered in this analysis. Mass and energy flow through the EAF are shown in Figure 5. The mass and energy flow through the EAF are shown in Equations (18) and (19).

Mass balance

$$
M_{4}+M_{9}+M_{10}+M_{11}=M_{6}+M_{8}+M_{7}
$$

Energy balance

$$
M_{4} * h_{4}+\beta_{e l} * E L_{E A F}=M_{6} * h_{6}+M_{8} * h_{8}+M_{7} * h_{7}+\delta_{\text {heat losses }}
$$




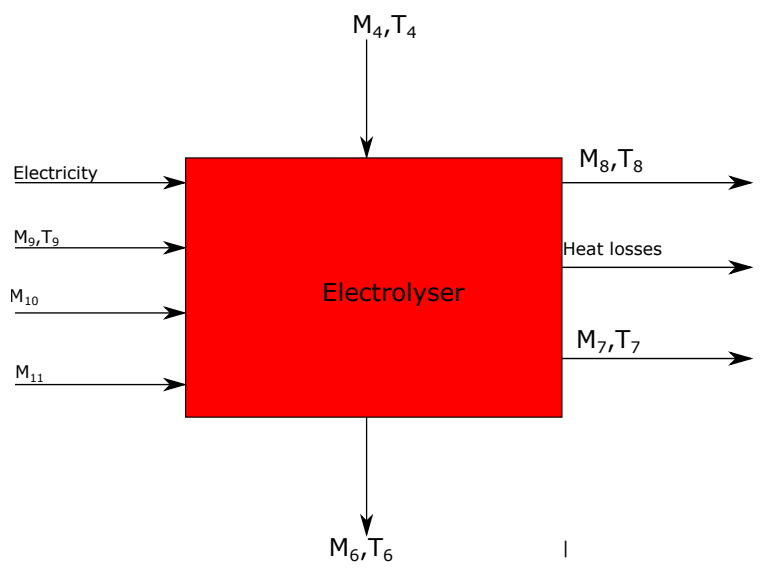

Figure 5. Mass and energy flow through the electric arc furnace.

\subsection{Electrolyzer}

Alkaline or PEM electrolyzers could be used in the system configuration presented in the model for hydrogen production. An alkaline electrolyzer has been considered in the present model owing to the lower capital cost of alkaline electrolysers [62] and their use in HYBRIT project [63] for a pilot project on hydrogen-based direct reduction of iron ore in Sweden. Technical specifications of the electrolyzer have been taken from 20 MW electric alkaline electrolyzer module produced by Thyssenkrupp industries [64]. Excess hydrogen produced during off-peak hours could be fed into the pressurized hydrogen storage tank. Dynamic operation of the electrolyzer has not been considered in the model. Electricity from the grid or from a dedicated renewable energy generation system could be utilized in the electrolyzer [65]. Mass and energy flow through the electrolyzer is presented in Figure 6.

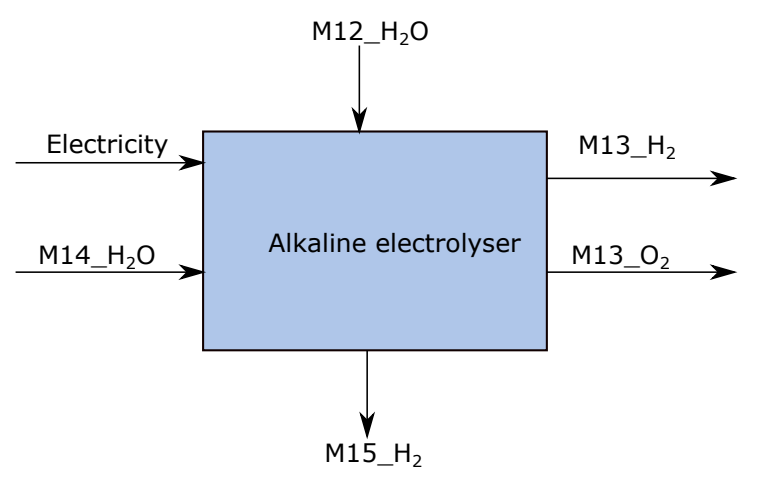

Figure 6. Mass and energy flow through the electrolyzer.

Mass balance

$$
\begin{aligned}
& M_{12_{\mathrm{H}_{2} \mathrm{O}}}+M_{14_{\mathrm{H}_{2} \mathrm{O}}}=M_{13_{\mathrm{H}_{2}}}+M_{15_{\mathrm{H}_{2}}}+M_{13_{\mathrm{O}_{2}}} \\
& M_{13}=M_{13_{H_{2}}}+M_{13_{\mathrm{O}_{2}}} \text {. }
\end{aligned}
$$

Energy balance

Energy consumption of the electrolyzer $\left(E L_{s} p e c\right)$ is assumed to be $45 \mathrm{KWh} / \mathrm{kgH}_{2}$. In practice, efficiency of the electrolyzer varies with current density and hydrogen output. For a more detailed analysis of the operations and energy balance of the electrolsyer, readers could refer to [65-67].

$$
E L_{\text {elec }}=\left(M_{13_{\mathrm{H}_{2}}}+M_{15_{\mathrm{H}_{2}}}\right) * E L_{\text {spec }} .
$$




\subsection{Waste Gas Separation Unit}

Unreacted hydrogen is separated from the waste gas stream using a pressure swing adsorber [68,69]. Mass and energy flows through the pressure swing adsorber are shown in Figure 7. Pressure swing adsorbers have been used for industrial production of hydrogen in ammonia plants [70,71]. The temperature of the incoming waste gas stream was assumed to be $250{ }^{\circ} \mathrm{C}$. Water separated from the waste stream is fed back to the electrolyzer. The energy required to run the pressure swing adsorber has not been considered in this model. It has been assumed that the water and hydrogen stream are free of impurities.

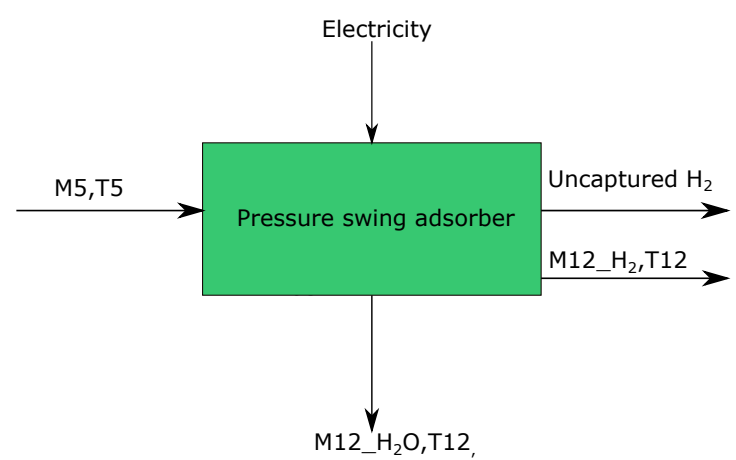

Figure 7. Mass and energy flow through the waste gas separation unit.

Mass balance

$$
M_{5_{H_{2}}}+M_{5_{H_{2 O}}}=M_{12_{H_{2}}}+M_{12_{H_{2} \mathrm{O}}}+\delta_{H_{2}}
$$

Energy balance

$$
M_{5} * h_{5}+E l_{\text {separator }}=M_{12_{\mathrm{H}_{2}}} * h_{12_{\mathrm{H}_{2}}}+M_{12_{\mathrm{H}_{2} \mathrm{O}}} * h_{12_{\mathrm{H}_{2} \mathrm{O}}}+\delta_{\text {heat losses }}+\gamma_{\mathrm{H}_{2}}
$$

\subsection{Electric Heater for Hydrogen Stream}

Electrical heater, with an efficiency of 0.6 has been considered for heating the hydrogen gas stream entering the shaft furnace to a temperature of $500{ }^{\circ} \mathrm{C}$. Hydrogen gas stream entering the electrical heater is a mixture of hydrogen coming from the electrolyser at $90{ }^{\circ} \mathrm{C}$ and hydrogen separated in the pressure swing adsorbers at $250{ }^{\circ} \mathrm{C}$. The mass and energy flow of the electrical heating unit is shown in Figure 8.

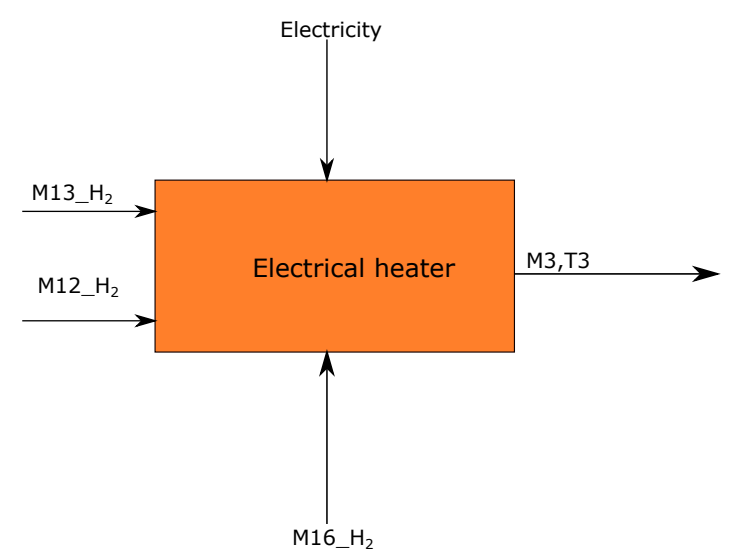

Figure 8. Mass and energy balance through the electrical heating unit for hydrogen stream. 
Mass balance

$$
M_{3}=M_{13_{H_{2}}}+M_{12_{H_{2}}}
$$

Energy balance

$$
M_{12_{\mathrm{H}_{2}}} * h_{12_{\mathrm{H}_{2}}}+M_{13_{\mathrm{H}_{2}}} * h_{13_{\mathrm{H}_{2}}}+\text { EL heating }=M_{3} * h_{3}+\delta_{\text {heat losses }}
$$

\section{Results and Discussions}

The modeling results are presented in this section. It has been assumed that the ore contains five percent impurities and the metallization rate of 0.94 is achieved in the DRI shaft furnace in the base case [34]. Modeling results have been compared with the energy consumption and emission values reported in the literature for the HDRI-EAF system.

\subsection{Mass and Energy Flow}

Mass and energy flow through the different components of the HDRI-EAF system are presented in Table 1. Hydrogen entering the shaft furnace was considered to be 1.5 times the stoichiometric value $(\lambda=1.5)$. Exhaust stream from the EAF, $M_{8}$, comprising of $\mathrm{CO}_{2}$ and $\mathrm{CO}$ was not calculated as the composition and temperature are dependent on the operation of the EAF. Carbon, $M_{10}$, was added to the system at a fixed rate of $10 \mathrm{~kg} / \mathrm{tl}$. It was assumed that $50 \mathrm{~kg} / \mathrm{tls}$ of Lime and $\mathrm{MgO}, M_{11}$, is added to the EAF. Oxygen, $M_{9}$, was added in the EAF for production of $\mathrm{CO}$. Hydrogen flow from the storage, $M_{15}$ and $M_{16}$, was not considered in the model.

Table 1. Mass and energy flow through the DRI-EAF system. N.A refers to not available or not calculated.

\begin{tabular}{cccccc}
\hline Stream & Mass Flow (ton/tls) & Temperature $\left({ }^{\circ} \mathbf{C}\right)$ & Energy $(\mathbf{K W h})$ & Short Description & Process Step \\
\hline$M_{1}$ & 1.599 & 25 & N.A & Iron ore pellets & Pellet heater \\
$M_{2}$ & 1.599 & 800 & 370.78 & Heated iron ore pellets & Pellet heater \\
$M_{3}$ & 0.0812 & 500 & 155.59 & $\mathrm{H}_{2}$ entering the shaft furnace & Shaft furnace \\
$M_{4}$ & 1.063 & 700 & 107.498 & Metallic stream exiting the shaft furnace & Shaft furnace \\
$M_{5_{H_{2}}}$ & 0.027 & 250 & 24.45 & $\mathrm{H}_{2}$ from waste stream & Shaft furnace \\
$M_{\mathrm{H}_{2} \mathrm{O}}$ & 0.483 & 250 & 82.18 & $\mathrm{H}_{2} \mathrm{O}$ from Waste stream & Shaft furnace \\
$M_{6}$ & 1 & 1650 & 239.15 & Molten steel exiting the EAF & EAF \\
$M_{7}$ & 0.149 & 1650 & 54.25 & Slag exiting the EAF & EAF \\
$M_{12_{H_{2}}}$ & 0.021 & 250 & 5.613 & $\mathrm{H}_{2}$ exiting the adsorber & Adsorber \\
$M_{12} 2_{H_{2} \mathrm{O}}$ & 0.483 & 90 & N.A & $\mathrm{H}_{2} \mathrm{O}$ exiting the adsorber & Adsorber \\
$M_{13} \mathrm{H}_{2}$ & 0.059 & 90 & 53.80 & H from electrolyzer & Electrolyzer \\
$M_{14}$ & 0.171 & 25 & N.A & $\mathrm{H}_{2} \mathrm{O}$ entering the electrolyzer & Electrolyzer \\
\hline
\end{tabular}

\subsection{Electricity Consumption}

Variation of electricity consumption with a change in the mass flow of hydrogen is shown in Figure 9. Total energy consumption varied from 3.4 to $5.91 \mathrm{MWh} / \mathrm{tls}$, as $\lambda$ is varied from one to five. Specific energy consumption (SEC) of the HDRI-EAF system at $3.72 \mathrm{MWh} / \mathrm{tls}(\lambda=1.5)$ system was higher than the BF-BOF based steel production, which has an SEC of 3.48 MWh. All the energy in the HDRI-EAF system was consumed in the form of electricity. Electricity is required for pellet heating, hydrogen production, heating the hydrogen stream entering the shaft furnace and melting of iron in the electric arc furnace. Switching from BF-BOF to HDRI-EAF based steel production would lead to an additional electricity demand of $375 \mathrm{TWh}$ in the EU. It was observed that increasing the mass flow of hydrogen in the DRI shaft furnace, increases energy consumption in the electrolyzer and in the electric heater for hydrogen heating.

Approximately, $436 \mathrm{KWh} / \mathrm{tls}$ of electricity was used for heating the iron ore pellets to the reaction temperature of $800^{\circ} \mathrm{C}$. Waste gases exiting the DRI shaft furnace could be used for pre-heating the iron ore pellets. Endothermic reduction reaction of iron oxide with hydrogen requires $334 \mathrm{KWh}$ of energy. Pre-heating the hydrogen stream entering the shaft furnace requires $160 \mathrm{KWh}$ of electricity. 
The electrolyzer consumed $2680 \mathrm{KWh}$ of electricity, which was approximately $70 \%$ of the total energy consumed in the HDRI-EAF system. The performance of electrolyzer and mass flow of hydrogen has a significant impact on the overall energy consumption of the system. As stated in Section 2, the type of raw material, temperature of the reduction reaction and design of the reactor have an impact on the mass flow of hydrogen for optimal reaction rate. In order to reduce the energy consumption, design of the reactor and the operating conditions could be optimized for a lowering the $\lambda$ value. EAF consumes $445 \mathrm{KWh} / \mathrm{tl}$ of electrical energy. EAF energy consumption increases at lower metallization rates. If the amount of impurities in the iron ore pellet increased, a similar trend in energy consumption of the EAF could be observed. The value of EAF energy consumption decreases at higher DRI temperatures.

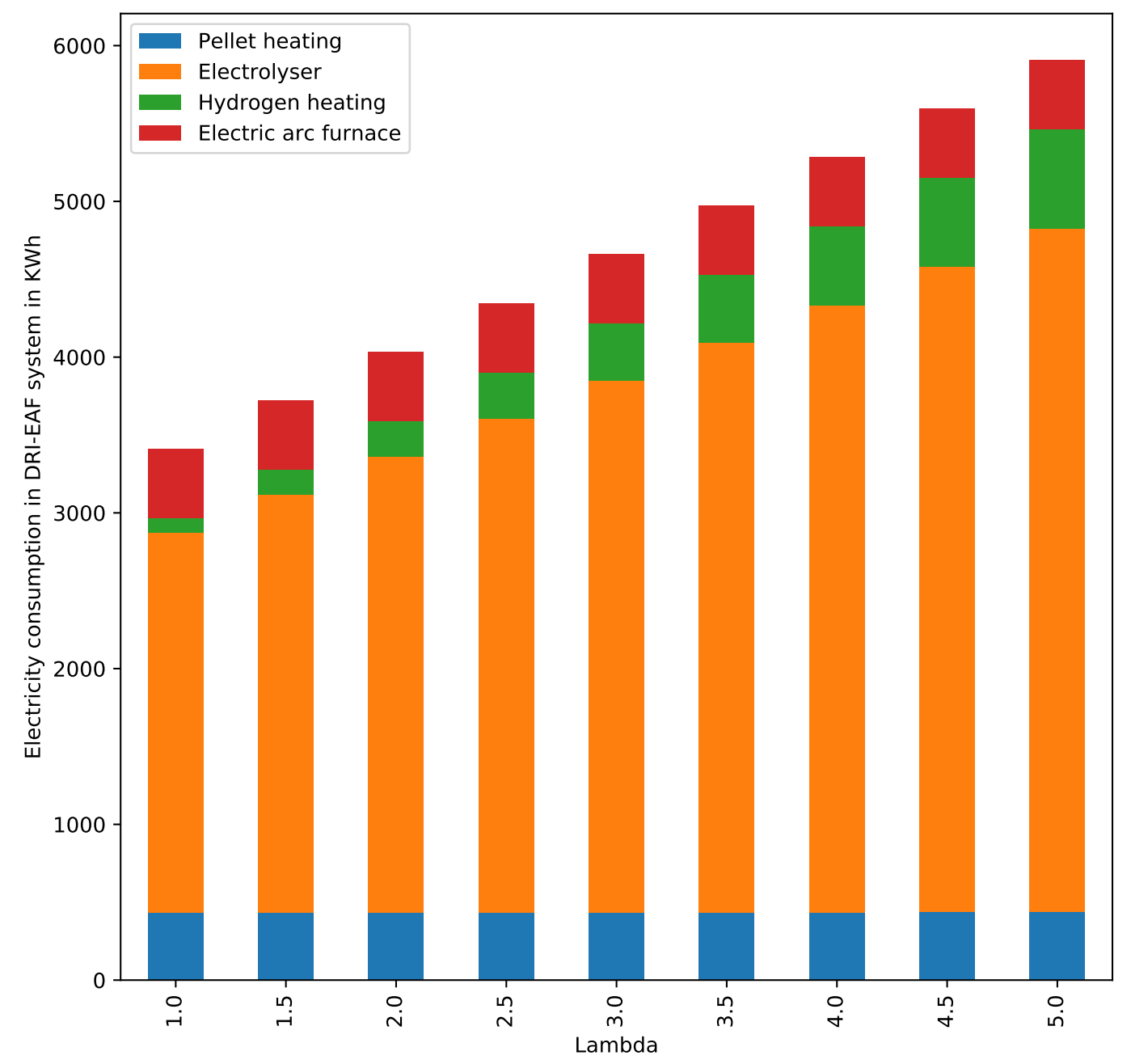

Figure 9. Variation of electricity demand (in KWh) in DRI-EAF system with varying mass flow rate of hydrogen in the DRI shaft furnace.

Waste Gas Enthalpy

The enthalpy of waste gas exiting the shaft furnace varies with temperature and flow rate of incoming hydrogen stream, as shown in Figure 10. Although majority of the outgoing energy could be captured by mixing the incoming hydrogen stream with the waste gas hydrogen stream, an optimal design of the shaft furnace and operating conditions would ensure lower losses through the waste stream. 


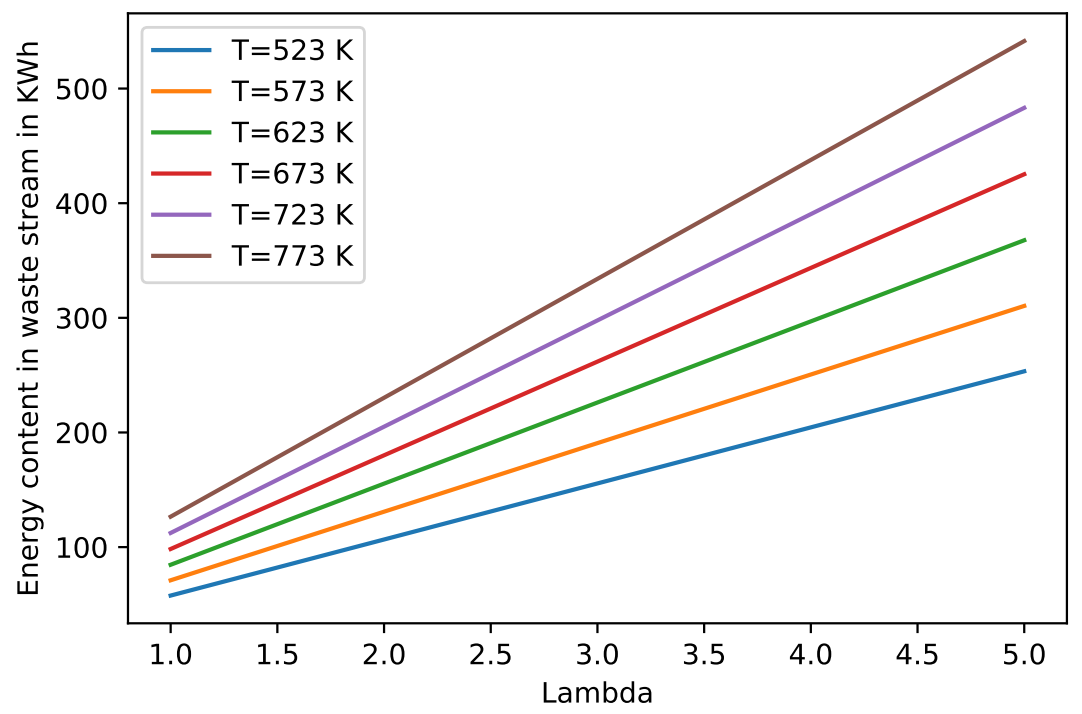

Figure 10. Waste gas enthalpy variation with temperature and mass flow rate of input hydrogen.

\subsection{Emissions from the HDRI-EAF System}

Emissions are directly related to the amount of electricity used in the HDRI-EAF system. A small amount of emission is also produced in the EAF, as a result of the reduction of wustite with carbon and from the oxidation of carbon to $\mathrm{CO}$ and to $\mathrm{CO}_{2}$ subsequently. These emissions were not considered. The emission intensity of the system varies with the grid emission factor of the countries, as shown in Figure 11.

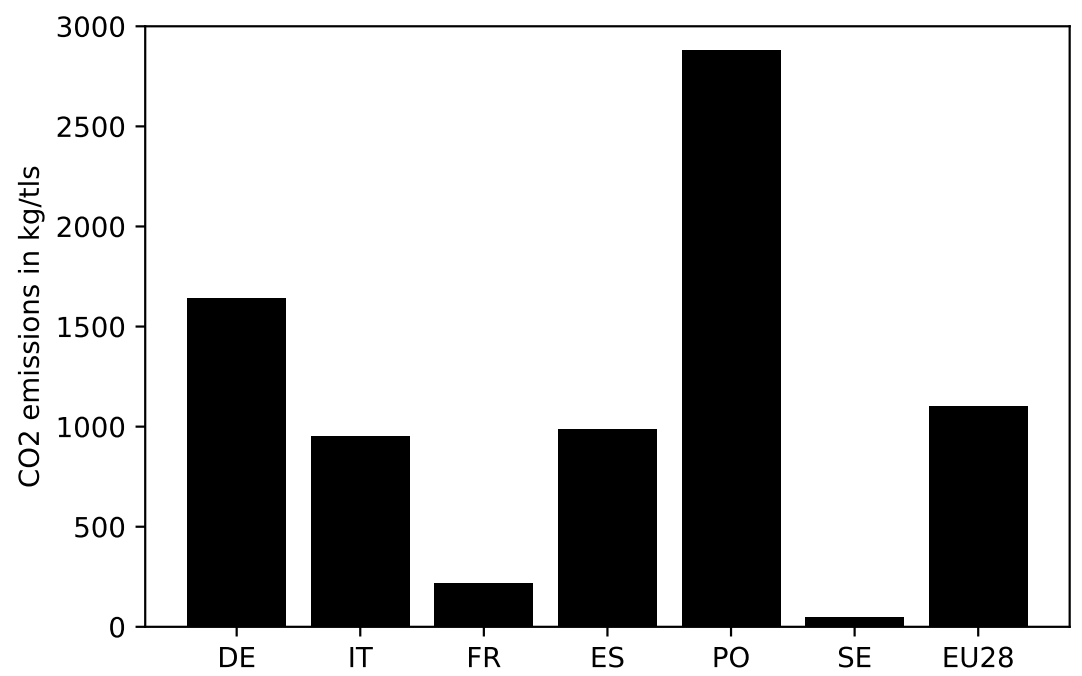

Figure 11. $\mathrm{CO}_{2}$ emission variation with countries in $\mathrm{kgCO} 2 / \mathrm{tls}$.

Emission intensity of BF-BOF process is $1688 \mathrm{kgCO}_{2} / \mathrm{tls}$ in the $\mathrm{EU}$ [72], which is much higher than the HDRI-EAF's emission intensity of $1101 \mathrm{kgCO}_{2} / \mathrm{tls}$ (at EU's grid emission factor of $295 \mathrm{kgC}_{2} / \mathrm{MWh}$ ). Modeling results show that the emissions from the production of steel in the HDRI-EAF system would be lower in most EU countries at present grid emission levels, except Poland. The grid emission factor of Poland is $773 \mathrm{gCO}_{2} / \mathrm{KWh}$, which is more than twice the EU average of $295 \mathrm{gCO}_{2} / \mathrm{KWh}$. The emission intensity of HDRI-EAF based steel production could be reduced to $415 \mathrm{kgCO}_{2} / \mathrm{tls}$ in countries with low grid emission factors like Sweden. If electricity is provided from renewable energy sources then it would result in a reduction of $170.26 \mathrm{MtCO}_{2}$ annually. The use of HDRI-EAF based steel production could increase the emissions from steel production in countries with a grid emission factor higher than $456 \mathrm{gCO}_{2} / \mathrm{KWh}$. 


\subsection{Comparison with Literature Values}

Specific energy consumption (SEC) and emission for production of 1 ton of liquid steel have been compared with the results available in the literature, shown in Figure 12. The grid emission factor of the German electricity grid has been considered for emission calculations, which is $440.9 \mathrm{gCO}_{2} / \mathrm{KWh}$. Emission values were not reported by Vogl et al. [34] and Fischedick et al. [7], emissions associated with the use of electricity from the German electric grid have been considered for comparison. The mass flow rate of hydrogen was not specified by Otto et al. [32] and Fischedick et al. [7], the $\lambda$ value of 1.5 was assumed as specified by Vogl et al. [34]. SEC of $3.72 \mathrm{MWh}$, corresponding to $\lambda$ value of 1.5 has been considered for the comparison.

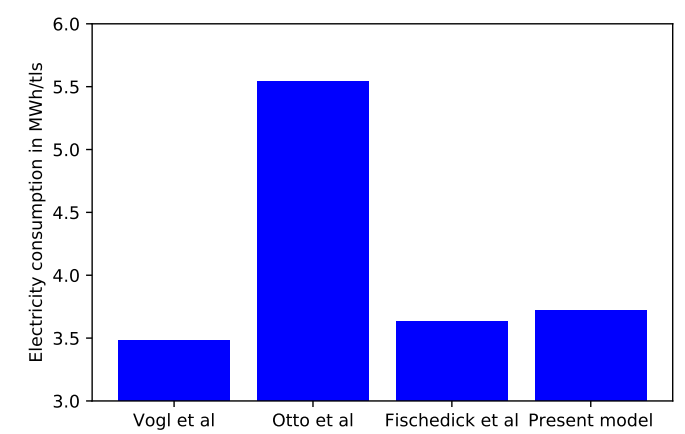

(a)

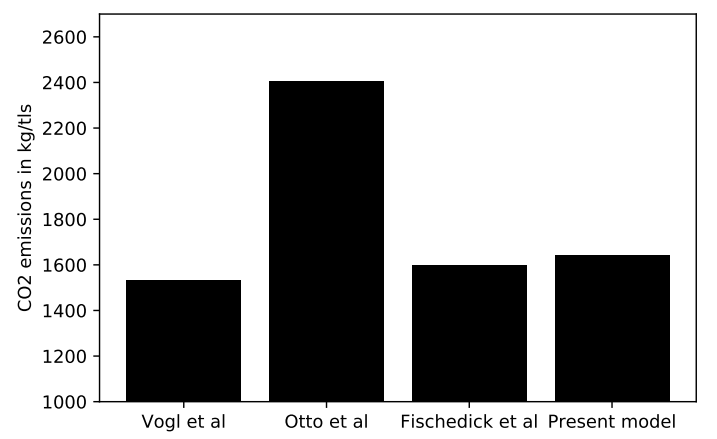

(b)

Figure 12. (a) Comparison of energy demand for hydrogen direct reduction of iron ore with literature values. (b) Comparison of $\mathrm{CO}_{2}$ emission from hydrogen direct reduction of iron ore with literature values.

The difference in the SEC and emission intensity could stem from the different system configurations considered. Otto et al. [32] have considered the Circored process, which uses a fluidized bed reactor instead of a shaft furnace. The use of natural gas for pellet heating and other process steps increases the energy and emission intensity in the circored process. Electric energy has been considered for pre-heating the pellets and incoming hydrogen stream, instead of a waste heat utilization unit as described by Vogl et al. [34]. It has been assumed that $80 \%$ of the hydrogen gas available in the waste stream will be adsorbed, and the remaining $20 \%$ will be generated in the electrolyzer.

\subsection{Energy Consumption and Emissions in EU Countries}

The impact of transitioning to HDRI-EAF based primary steel production on energy demand and emissions in different EU countries has been evaluated in this section. Steel production data has been taken from the integrated database of the European energy sector(IDEES) [72]. The reference year for the steel production data is 2015. Additional energy consumption and emissions arising from pellet making, sintering, and steel finishing processes have also been considered in this analysis. The results are presented in Figure 13. The energy requirement for steel production could increase from 493 TWh to $517 \mathrm{TWh}$ for EU-28 by switching to HDRI-EAF based steel production. At the same time, emissions from steel production could be reduced from 193 million tonnes of $\mathrm{CO}_{2}$ /year to approximately 134 million tonnes of $\mathrm{CO}_{2}$ /year. Considering the price of carbon to be $30 € /$ ton of $\mathrm{CO}_{2}$ in the EU, it is estimated that HDRI-EAF based steel production could lead to a saving of $18 € /$ ton of steel, at present grid emission levels in the EU. The savings could be much higher in the future with increasing $\mathrm{CO}_{2}$ prices and a reduction in the grid emission factor. 


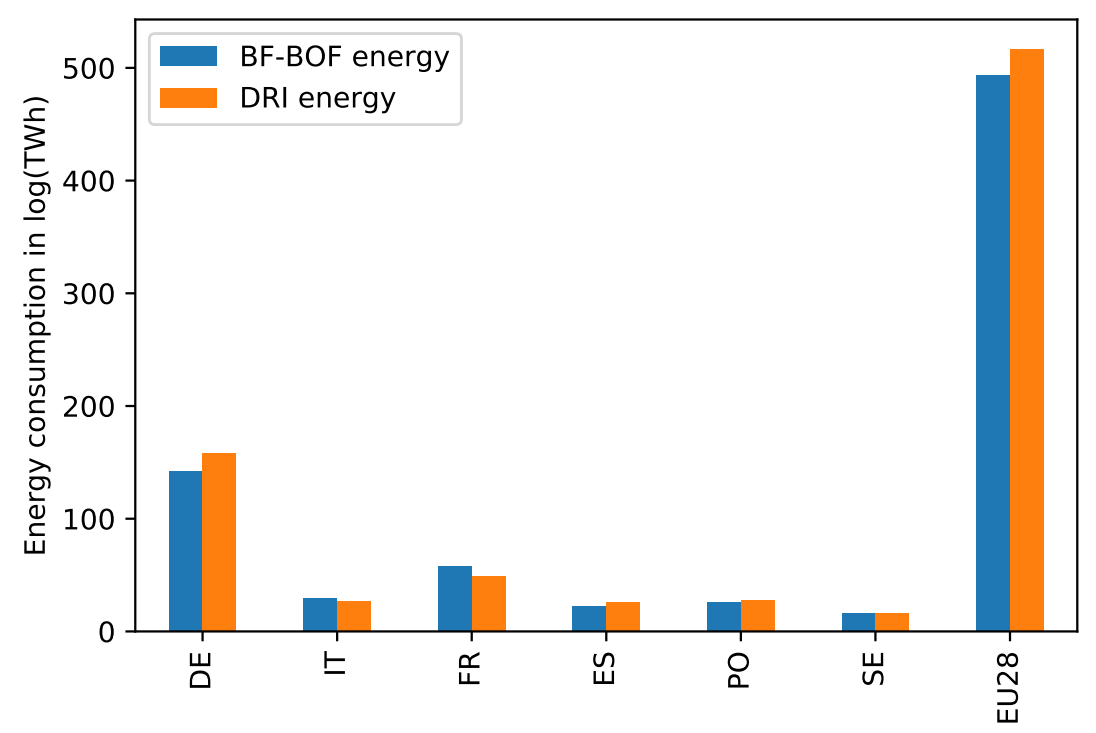

(a)

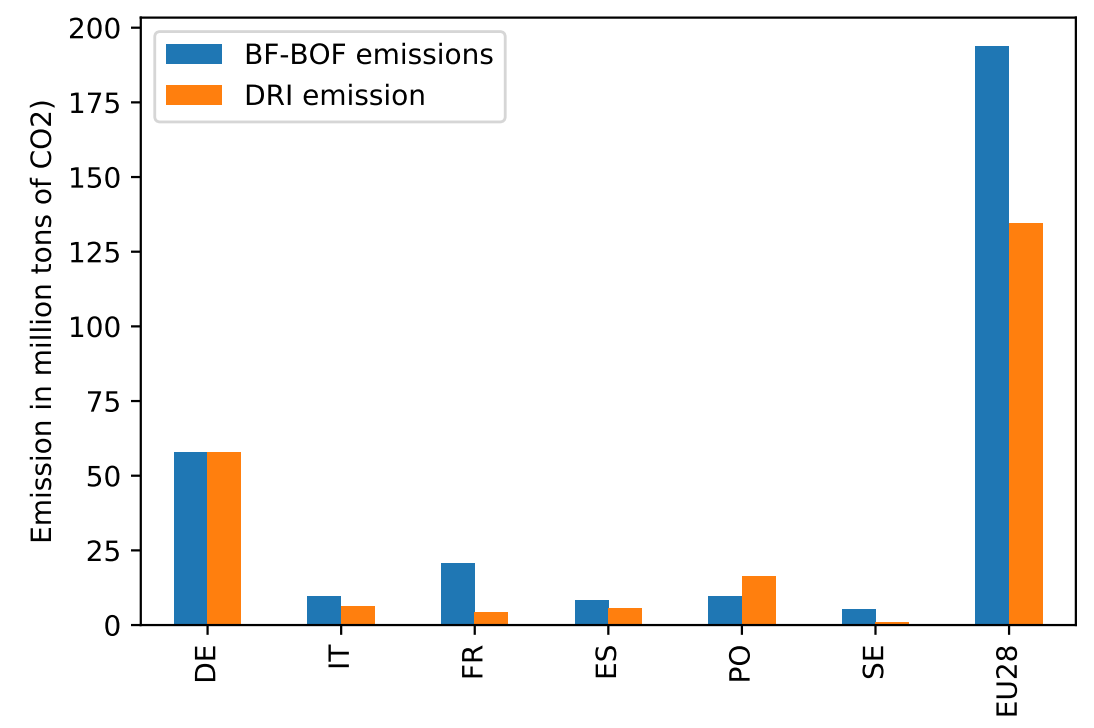

(b)

Figure 13. (a) Comparison of present energy demand from primary steel production in EU countries and projected energy demand for conversion to hydrogen direct reduction of iron ore (HDRI)-EAF based steel production. (b) Comparison of present emissions from primary steel production in EU countries and projected emissions for complete conversion to HDRI-EAF based steel production.

\subsection{Sensitivity Analysis}

Local sensitivity analysis [73] was carried out by varying the input parameters by $\pm 5 \%, \pm 10 \%$, $\pm 15 \%, \pm 20 \%$ one-at-a-time and keeping other parameters fixed. The parameters considered for the sensitivity analysis are hydrogen mass flow rate $(\lambda)$, electrolyzer efficiency, hydrogen input temperature(T3), EAF input temperature (T4), adsorber efficiency and the grid emission factor. The results of the sensitivity analysis are presented in Figure 14.

Sensitivity analysis revealed that electrolyzer output affects the electricity consumption of the EAF-DRI system. Electrolyzer output is an indicator of the electrolyzer efficiency in terms of the amount of electricity required for the production of one $\mathrm{kg}$ of hydrogen $\left(\mathrm{KWh} / \mathrm{kgH}_{2}\right)$. Another important parameter affecting the electricity consumption is $\lambda$, which is a ratio of the actual hydrogen required for production of one ton of liquid steel to the stoichiometric requirement of hydrogen. The 
value of $\lambda$ is related to the design of the shaft furnace reactor and operating conditions. Electricity requirement of the system decreases as the adsorption efficiency increases in the pressure swing adsorption system. Emissions from the system are strongly correlated with the grid emission factor. Electrolyzer output, lambda and the adsorption factor are important factors, which decide the overall emissions from the system, as they are directly related to the electricity consumption of the HDRI-EAF system. Hydrogen input temperature (T3) and the EAF input temperature (T4) do not have a major impact on the energy requirement and emissions from the HDRI-EAF system.

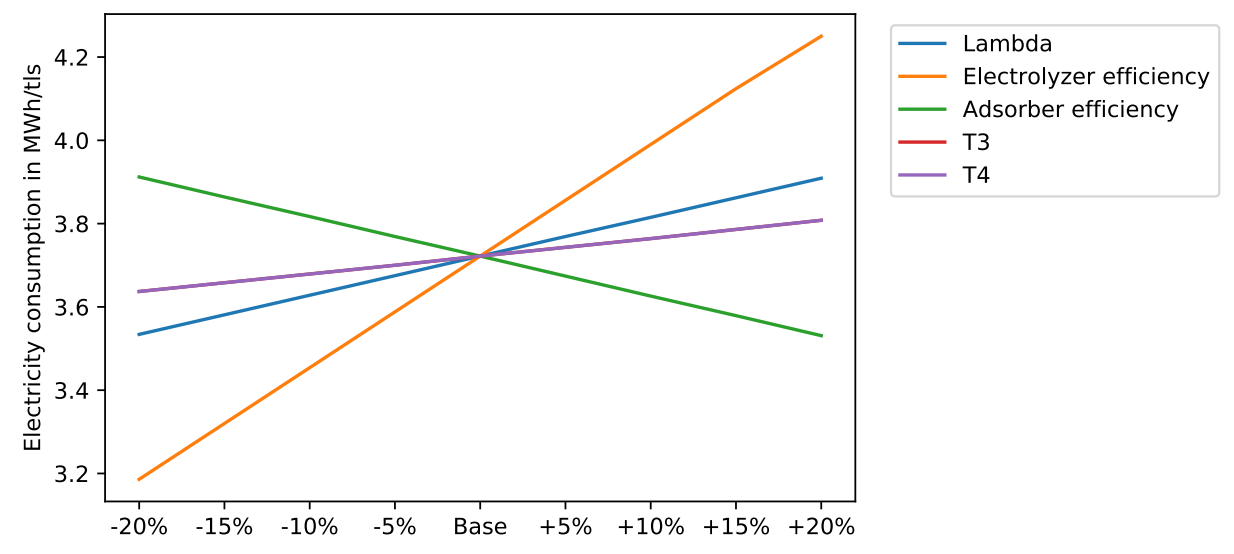

(a)

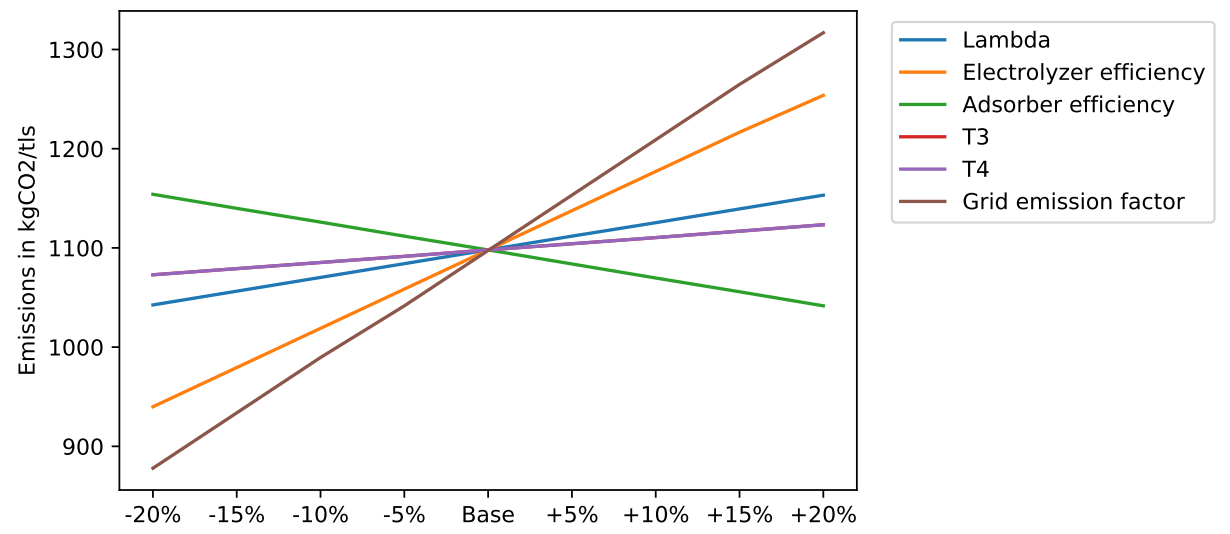

(b)

Figure 14. (a) Sensitivity analysis to identify the parameters affecting the electricity requirements of the HDRI-EAF system. (b) Sensitivity analysis to identify the most important parameters affecting the $\mathrm{CO}_{2}$ emission from the HDRI-EAF system.

\section{Conclusions}

HDRI-EAF based steel production is a viable alternative to BF-BOF based steel production, but adoption of the technology would depend on the future cost of electrolyzers and electricity. Sensitivity analysis revealed that electrolyzer efficiency is the most important factor affecting the system energy consumption, while the grid emission factor is strongly correlated with the overall system emissions. Recent improvements in the performance of electrolyzers could reduce the energy consumption and emissions from the HDRI-EAF based steel production. The iron and steel industry could play a major role in the transition to the hydrogen economy by creating a demand for large quantities of hydrogen, which could lead to the development of infrastructure for generation, storage, and safe transport of hydrogen. The use of hydrogen in steel making coupled with hydrogen storage could provide flexibility to the electricity grid to integrate intermittent renewable energy sources and open new 
opportunities for revenue generation for steel companies by participating in the power reserve markets. Other strategies for flexible operation of the HDRI-EAF system could be explored by storing the DRI and operating the EAF according to electricity prices. Dynamic modeling of the HDRI-EAF system could quantify the potential of the steel industry to participate in the demand response market.

\section{Future Work}

In the future works, the techno-economical performance of DRI-EAF based system coupled with different hydrogen production technologies will be compared under different scenarios. The price of electricity and carbon costs would be varied to see their impact on the cost of steel production. The impact of using grid electricity on the costs and performance of the system would be compared with using dedicated renewable energy generators. Different hydrogen production technologies with varying system configurations like solid oxide electrolysis, methane pyrolysis and steam methane reforming with CCS would be considered for the production of hydrogen. Large scale generation and storage of hydrogen for steel production could have a substantial impact on other sectors of the energy system like energy generation, transport, buildings etc. The integration of HDRI-EAF based steel production in an energy system model could highlight these interactions, which could assist policy-makers to make more informed decisions.

Author Contributions: All authors have contributed equally in the work. All authors have read and agreed to the published version of the manuscript.

Funding: This project has received funding from the European Unions Horizon 2020 research and innovation programme under the Marie Skłodowska-Curie grant agreement No 765515.

Conflicts of Interest: The authors declare no conflict of interest.

\section{Abbreviations}

The following abbreviations and symbols are used in this manuscript:

$\begin{array}{ll}\text { Abbreviations } & \\ \text { DRI } & \text { Direct reduced iron } \\ \text { HDRI } & \text { Hydrogen direct reduced iron } \\ \text { EAF } & \text { Electric arc furnace } \\ \text { BF-BOF } & \text { Blast furnace basic oxygen furnace } \\ \text { SMR } & \text { Steam methane reforming } \\ \text { BASF } & \text { Badische Anilin und Soda Fabrik } \\ \text { SSAB } & \text { Svenskt Stål AB } \\ \text { LKAB } & \text { Luossavaara-Kiirunavaara Aktiebolag } \\ \mathrm{MMBTU} & \text { Metric Million British Thermal Unit } \\ \mathrm{SEC} & \text { Specific energy consumption } \\ \mathrm{TLS} & \text { Ton of liquid steel } \\ \mathrm{kgCO} & \text { Kilogram of carbon dioxide } \\ \mathrm{GtCO} & \text { Gigaton of carbon dioxide } \\ \mathrm{kg} & \text { kilogram } \\ \mathrm{kJ} & \text { KiloJoule } \\ \mathrm{KWh} & \text { Kilowatthour } \\ \mathrm{MWh} & \text { Megawatthour } \\ \$ & \text { US Dollar } \\ € & \text { Euro }\end{array}$


Symbols

$M_{1}$

$\mathrm{M}_{2}$

$\mathrm{Fe}_{2} \mathrm{O}_{3}$ pure

$\mathrm{FeO}_{\text {ratio }}$

$E L_{\text {pel heater }}$

$h_{1}$

$h_{2}$

$\eta_{e l}$

$\mathrm{M}_{\mathrm{H}_{2}}$

$\mathrm{H}_{2 \text { per mole }}$

$\mathrm{H}_{2 \text { molecular weight }}$

$F e_{\text {molecular weight }}$

$M_{4 \mathrm{FeO}}$

$\mathrm{M}_{4 \mathrm{Fe}}$

$M_{4_{\text {im }}}$

$\alpha$

$M_{5}$

$\mathrm{M}_{5_{\mathrm{H}_{2}}}$

$\mathrm{M}_{5_{\mathrm{H}_{2} \mathrm{O}}}$

$h_{3}$

$h_{4}$

$h_{5}$

$h_{5_{H_{2}}}$

$h_{5_{\mathrm{H}_{2} \mathrm{O}}}$

$H_{\text {reaction }}$

$\delta$

$M_{6}$

$h_{6}$

$M_{7}$

$h_{7}$

$M_{8}$

$h_{8}$

$\mathrm{M}_{9}$

$M_{10}$

$M_{11}$

$\beta_{e l}$

$E L_{E A F}$

$M_{12 \mathrm{H}_{2} \mathrm{O}}$

$\mathrm{M}_{12 \mathrm{H}_{2}}$

$h_{12 \mathrm{H}_{2}}$

$\mathrm{M}_{14 \mathrm{H}_{2} \mathrm{O}}$

$\mathrm{M}_{13 \mathrm{H}_{2}}$

$h_{13 H_{2}}$

$\mathrm{M}_{15 \mathrm{H}_{2}}$

$\mathrm{M}_{13 \mathrm{O}_{2}}$

EL $L_{\text {spec }}$

$E L_{\text {elec }}$

$\gamma_{H_{2}}$

EL heating
Mass of iron ore at heater inlet for production of 1 ton of liquid steel in $\mathrm{kg} / \mathrm{tls}$

Mass of iron ore at heater outlet for production of 1 ton of liquid steel in $\mathrm{kg} / \mathrm{tls}$

Percentage of pure iron ore in the iron ore stream (assumed to be 0.95)

Ratio of molecular weight of iron contained in iron oxide (0.7)

Electrical energy required for heating the pellets in $\mathrm{kJ}$

Specific enthalpy of iron ore at ambient temperature in $\mathrm{kJ} / \mathrm{kg}$

Specific enthalpy of iron ore at reactor temperature in $\mathrm{kJ} / \mathrm{kg}$

Efficiency of the electrical heater

Stoichiometric mass flow of hydrogen in $\mathrm{kg} / \mathrm{tls}$

1.5 Moles of hydrogen required for production of one mole of iron

$2.015 \mathrm{~g} / \mathrm{mol}$

$55.845 \mathrm{~g} / \mathrm{mol}$

Mass of FeO exiting the shaft furnace in $\mathrm{kg} / \mathrm{tls}$

Mass of Fe exiting the shaft furnace in $\mathrm{kg} / \mathrm{tls}$

Mass of impurities exiting the shaft furnace

Metallization rate

Mass flow of exhaust gases from the shaft furnace in $\mathrm{kg} / \mathrm{tls}$

Mass of unused hydrogen as exhaust from the DRI shaft furnace in $\mathrm{kg} / \mathrm{tls}$

Mass of water/steam produced as exhaust from the DRI shaft furnace in $\mathrm{kg} / \mathrm{tls}$

Specific enthalpy of hydrogen entering the shaft furnace in $\mathrm{kJ} / \mathrm{kg}$

Specific enthalpy of metallic stream exiting the shaft furnace in $\mathrm{kJ} / \mathrm{kg}$

Specific enthalpy of DRI exhaust gases in $\mathrm{kJ} / \mathrm{kg}$

Enthalpy of unreacted hydrogen from the DRI shaft furnace in $\mathrm{kJ} / \mathrm{kg}$

Enthalpy of water/steam from the DRI shaft furnace in $\mathrm{kJ} / \mathrm{kg}$

Reaction enthalpy of the reduction reaction in $\mathrm{kJ} / \mathrm{kg}$

Heat losses

Mass of molten metal from the EAF in Tons

Specific enthalpy of molten metal exiting the EAF in $\mathrm{kJ} / \mathrm{kg}$

Mass of scrap from the scrap in $\mathrm{kg} / \mathrm{tls}$

Specific enthalpy of scrap exiting the EAF in $\mathrm{kJ} / \mathrm{kg}$

Mass of exhaust gases exiting the EAF in $\mathrm{kg} / \mathrm{tls}$

Specific enthalpy of exhaust gases exiting the EAF in $\mathrm{kJ} / \mathrm{kg}$

Mass of oxygen entering the EAF in $\mathrm{kg} / \mathrm{tls}$

Mass of carbon added in the EAF in $\mathrm{kg} / \mathrm{tls}$

Mass of lime and dolomite added in the EAF in $\mathrm{kg} / \mathrm{tls}$

Efficiency of the EAF for conversion from electricity to heat

Electricity supplied to the EAF in $\mathrm{KWh} / \mathrm{tls}$

Mass of water entering the electrolyzer from the waste gas separation unit in $\mathrm{kg}$

Mass of hydrogen entering the electric heater in $\mathrm{kg}$

Enthalpy of hydrogen entering the electrolyzer from the waste gas separation unit in $\mathrm{kg}$

Mass of water supplied to electrolyzer externally in $\mathrm{kg}$

Mass of hydrogen produced in the electrolyzer and supplied to the DRI shaft furnace in $\mathrm{kg}$

Enthalpy of hydrogen produced in the electrolyzer and supplied to the DRI shaft furnace in $\mathrm{kg}$

Mass of hydrogen produced in the electrolyzer and supplied to the hydrogen storage in $\mathrm{kg}$

Mass of oxygen produced in the electrolyzer in $\mathrm{kg}$

Specific energy consumption of the electrolyzer in $\mathrm{KWh} \mathrm{kg}^{-1}$

Electricity consumption in the electrolyzer in KWh

Uncaptured hydrogen exiting the pressure swing adsorber

Electricity consumed for heating the hydrogen stream in $\mathrm{KWh} / \mathrm{tls}$ 


\section{Appendix A}

Some of the important assumptions made for the model are listed below:

1. All calculations are done for the production of 1 ton of liquid steel from the system.

2. Energy consumption and emissions related to iron ore mining, pellet making, and downstream steel finishing steps were not considered in this analysis.

3. $5 \%$ impurities are present in the raw materials. The assumption is consistent with the plant data available in the literature. The primary components of the impurities are silica and alumina.

4. The iron ore pellets are heated from ambient temperature to $800^{\circ} \mathrm{C}$, through an electrical heater of efficiency, $\eta_{\text {thermal }}=0.85$.

5. Output from the shaft furnace would be metallic $\mathrm{Fe}$ and $\mathrm{FeO}$. The remaining $\mathrm{FeO}$ will be reduced to pure iron in the electric arc furnace. Although, in practice, some amount of $\mathrm{FeO}$ does not get reduced and becomes a part of the EAF slag.

6. The flow rate of hydrogen is considered to be higher than the stoichiometric requirements.

7. Apparent activation energy of $35 \mathrm{~kJ} /$ mole has been considered in this model.

8. Hydrogen produced from electrolyzers is heated in an electrical heater with an efficiency of $\eta_{\text {thermal }}=0.6$.

9. DRI stream exiting the shaft furnace is considered to be at a temperature of $800{ }^{\circ} \mathrm{C}$.

10. The exhaust gas stream is assumed to be composed of hydrogen and water. The waste stream enthalpy varies with exhaust gas temperature and $\lambda_{h 2}$.

11. Energy required to separate hydrogen and water from the waste stream is not considered in the present calculations.

12. $100 \%$ DRI is fed into the furnace without any scrap. The quality of scrap has a significant effect on energy consumption in a DRI.

13. Hot DRI is fed into the DRI at $700{ }^{\circ} \mathrm{C}$ as it saves a considerable amount of electrical energy in the EAF.

14. Natural gas is not used for heating the material as its the general practice to use natural gas with scrap for initial heating.

15. As DRI is reduced only with Hydrogen, it is assumed that it does not contain any ferric carbide. Carbon required for reduction of remaining $\mathrm{FeO}$ in the EAF is supplied externally as coal or coke.

16. Temperature of the DRI being fed into the EAF is not taken into account into empirical energy models [74]. Thermodynamic modeling of the EAF has been done to get the specific energy consumption of the EAF with $100 \%$ DRI.

17. Iron ore pellets generally contain elements such as silicon, manganese, chromium, aluminium, sulphur, phosphorus, molybdenum etc. They get oxidized inside the electric arc furnace, releasing heat and assist in the melting of the iron ore. As iron ore pellets containing only alumina and silica have been considered in this model, additional energy supplied from the oxidation of these elements has not been considered, but a provision for their inclusion in future work has been made in the code.

18. Carbon is added into the EAF to reduce the remaining $\mathrm{FeO}$ in the mix and also to generate $\mathrm{CO}$ for froth formation, which is essential for the operation of the EAF and to extend the life of the graphite electrodes and the refractory.

19. $\mathrm{CaO}$ and $\mathrm{MgO}$ are added in the EAF as slag formers to maintain the basicity of the EAF. The weights of $\mathrm{CaO}$ and $\mathrm{MgO}$ used are according to data published in the literature [51].

20. Efficiency parameters used in the EAF model for electrical and chemical energy are according to the reference [51]. 


\section{References}

1. Arens, M.; Worrell, E.; Eichhammer, W.; Hasanbeigi, A.; Zhang, Q. Pathways to a low-carbon iron and steel industry in the medium-term-The case of Germany. J. Clean. Prod. 2017, 163, 84-98. [CrossRef]

2. UNFCCC's Technology Executive Commitee; UNFCCC. Industrial Energy and Material Efficiency in EmissionIntensive Sectors; Technical report, United nations framework convention for climate change; UNFCCC's Technology Executive Commitee: Copenhagen, Denmark, 2017. Available online: https://bit.ly/332v3j1 (accessed on 5 January 2020).

3. World Steel Association Statistics. 2017. Available online: https://www.worldsteel.org/internet-2017/steelby-topic/statistics/steel-data-viewer/P1\{_\}crude $\left\{_{-}\right\}$steel\{_\}total/CHN/IND/WORLD \{_\}ALL/JPN/DEU (accessed on 13 November 2019).

4. Arcelor Mittal: Climate Action Report. Available online: https:/ / corporate.arcelormittal.com/sustainability / arcelormittal-climate-action-report?frommobile=true (accessed on 8 September 2019).

5. Bataille, C.; Åhman, M.; Neuhoff, K.; Nilsson, L.J.; Fischedick, M.; Lechtenböhmer, S.; Solano-Rodriquez, B.; Denis-Ryan, A.; Stiebert, S.; Waisman, H.; et al. A review of technology and policy deep decarbonization pathway options for making energy-intensive industry production consistent with the Paris Agreement. J. Clean. Prod. 2018, 187, 960-973. [CrossRef]

6. Åhman, M.; Nilsson, L.J.; Johansson, B. Global climate policy and deep decarbonization of energy-intensive industries. Clim. Policy 2017, 17. [CrossRef]

7. Fischedick, M.; Marzinkowski, J.; Winzer, P.; Weigel, M. Techno-economic evaluation of innovative steel production technologies. J. Clean. Prod. 2014, 84, 563-580. [CrossRef]

8. Sarkar, S.; Bhattacharya, R.; Roy, G.G.; Sen, P.K. Modeling MIDREX Based Process Configurations for Energy and Emission Analysis. Steel Res. Int. 2018, 89, 1700248. [CrossRef]

9. Pardo, N.; Moya, J.A.; Vatopoulos, K. Prospective Scenarios on Energy Efficiency and $\mathrm{CO}_{2}$ Emissions in the EU Iron E Steel Industry; Technical Report LD-NA-25543-EN-C; Joint Research Council, European Union: Luxemburg City, Luxemburg, 2012. [CrossRef]

10. Wiencke, J.; Lavelaine, H.; Panteix, P.J.; Petitjean, C.; Rapin, C. Electrolysis of iron in a molten oxide electrolyte. J. Appl. Electrochem. 2018, 48, 115-126. [CrossRef]

11. Stel, J.V.D.; Hattink, M.; Sert, D.; Zagaria, M.; Eklund, N.; Pettersson, M.; Sundqvist, L.; Mefos, B.S.; Feilmayr, C.; Kinnunen, K.; et al. Developments of the ULCOS Low $\mathrm{CO}_{2}$ Blast Furnace Process at the LKAB Experimental BF in Luleå Abstract Key Words History of Recycling of Blast Furnace Top Gas. In Proceedings of the 1st International Conference on Energy Efficiency and $\mathrm{CO}_{2}$ Reduction in the Steel Industry, Dusseldorf, Germany, 1 July 2011; pp. 1-8.

12. IEA. Technology Roadmap Carbon Capture and Storage in Industrial Applications; IEA: Paris, France, $2011 ;$ p. 43.

13. Hydrogen Future Fuel Cell and Hydrogen Joint Undertaking. Technical Report June. 2019. Available online: https:/ / www.fch.europa.eu/sites/default/files/Hydrogen\%20Roadmap\%20Europe_Report.pdf (accessed on 5 January 2020).

14. The Future of Hydrogen: Seizing Today's Opportunities. Technical Report June. 2019. Available online: https: / / webstore.iea.org/the-future-of-hydrogen (accessed on 5 January 2020).

15. Hydrogen for Australia's Future. Technical Report August, Austrlian Government Chief Scientist. 2018. Available online: https:/ / bit.ly/2O0ASJA (accessed on 5 January 2020).

16. Philibert, C. Renewable Energy for Industry From Green Energy to Green Materials and Fuels; Technical report; International Energy Agency: Paris, France, 2017. Available online: https://webstore.iea.org/search?q= renewable+energy+for (accessed on 5 January 2020).

17. Nuber, D.; Eichberger, H.; Rollinger, B. Circored fine ore direct reduction. Millenium Steel 2006, 2006, 37-40.

18. Elmquist, S.A.; Weber, P.; Eichberger, H. Operational results of the Circored fine ore direct reduction plant in Trinidad. STAHL UND EISEN 2002, 59-64. Available online: https:/ / www.researchgate.net/publication/ 288144463_Operational_results_of_the_Circored_fine_ore_direct_reduction_plant_in_Trinidad (accessed on 5 January 2020). [CrossRef]

19. Duarte, P. Hydrogen-Based Steelmaking; Technical report; TenovaHYL: San Nicolás de los Garza, Mexico, 2015.

20. Armijo, J.; Philibert, C. Flexible production of green hydrogen and ammonia from variable solar and wind energy. Case study of Chile and Argentina. ResearchGate 2019. [CrossRef] 
21. Glenk, G.; Reichelstein, S. Economics of converting renewable power to hydrogen. Nat. Energy 2019, 4, 216-222. [CrossRef]

22. The Future of Hydrogen; Number June; OECD: Paris, France, 2019; p. 203. Available online: https:/ /www. oecd-ilibrary.org/energy/the-future-of-hydrogen\{_\}1e0514c4-en (accessed on 5 February 2020).

23. Hybrit Project-Pilot Projects. Available online: http://www.hybritdevelopment.com/articles/three-hybritpilot-projects (accessed on 5 January 2020).

24. H2future. h2future. Available online: https://www.h2future-project.eu/technology (accessed on 8 September 2019).

25. Salcos Salzgitter. Available online: https://salcos.salzgitter-ag.com/ (accessed on 8 September 2019).

26. Green Indsustrial Hydrogen: GrInHy2.0. Available online: https://www.green-industrial-hydrogen.com/ (accessed on 8 September 2019).

27. Windh2. Available online: https://www.windh2.de/ (accessed on 8 September 2019).

28. Brook, D. Tata Steel's European Operations Take Major Step Towards Becoming Carbon Neutral. 2018. Available online: https://www.tatasteeleurope.com/en/news/news/tata-steel-european-operations-takemajor-step-towards-becoming-carbon-neutral (accessed on 8 September 2019).

29. ArcelorMittal. World First for Steel: ArcelorMittal Investigates the Industrial Use of Pure HydrogenArcelorMittal. 2019. Available online: https:/ / corporate.arcelormittal.com/news-and-media/news/2019/ mar/28-03-2019 (accessed on 5 January 2020).

30. Langner, A.; Lorraine, L. ArcelorMittal Commissions Midrex to Design Demonstration Plant for Hydrogen Steel Production in Hamburg. 2019. Available online: https://corporate.arcelormittal.com/news-andmedia/news/2019/sep/16-09-2019 (accessed on 18 November 2019).

31. Thyssenkrupp. World First in Duisburg as NRW Economics Minister Pinkwart Launches Tests at Thyssenkrupp Into Blast Furnace Use of Hydrogen. 2019. Available online: https:/ / www.thyssenkruppsteel.com/en/newsroom/press-releases/world-first-in-duisburg.html (accessed on 13 November 2019).

32. Otto, A.; Robinius, M.; Grube, T.; Schiebahn, S.; Praktiknjo, A.; Stolten, D. Power-to-steel: Reducing $\mathrm{CO}_{2}$ through the integration of renewable energy and hydrogen into the German steel industry. Energies 2017, 10, 451. [CrossRef]

33. Cavaliere, P.; Cavaliere, P. Direct Reduced Iron: Most Efficient Technologies for Greenhouse Emissions Abatement; Springer: New York, NY, USA, 2019; pp. 419-484. [CrossRef]

34. Vogl, V.; Åhman, M.; Nilsson, L.J. Assessment of hydrogen direct reduction for fossil-free steelmaking. J. Clean. Prod. 2018, 203, 736-745. [CrossRef]

35. Wagner, D.; Devisme, O.; Patisson, F.; Ablitzer, D. A laboratory study of the reduction of iron oxides by hydrogen. 2006 TMS Fall Extr. Process. Divis. Sohn Int. Symp. 2006, 2, 111-120.

36. Abhinav, B. Hydrogen Direct Reduction of Iron Ore Using Green Hydrogen. Available online: https:/ / zenodo. org/record/3562399\#.XjpcSvkzaUk (accessed on 5 January 2020).

37. Spreitzer, D.; Schenk, J. Reduction of Iron Oxides with Hydrogen-A Review. Steel Res. Int. 2019, 90, 1900108. [CrossRef]

38. Hasanbeigi, A.; Price, L.; Chunxia, Z.; Aden, N.; Xiuping, L.; Fangqin, S. Comparison of iron and steel production energy use and energy intensity in China and the U.S. J. Clean. Prod. 2014, 65, 108-119. [CrossRef]

39. Small, M. Direct Reduction of Iron Ore. J. Metals 1981, 33, 67-75. [CrossRef]

40. Battle, T.; Srivastava, U.; Kopfle, J.; Hunter, R.; McClelland, J. The Direct Reduction of Iron. Treatise Process Metall. 2014, 3, 89-176. [CrossRef]

41. Anameric, B.; Kawatra, S.K. Properties and features of direct reduced iron. Mineral Process. Extr. Metall. Rev. 2007, 28, 59-116. [CrossRef]

42. Béchara, R.; Hamadeh, H.; Mirgaux, O.; Patisson, F. Optimization of the iron ore direct reduction process through multiscale process modeling. Materials 2018, 11, 1094. [CrossRef]

43. MIDREX. World Direct Reduction Statistics; Midrex Technologies, Inc.: Charlotte, NC, USA, 2013; p. 14.

44. Cheap Gas to Increase US Direct Reduced Iron Self Sufficiency. 2019. Available online: https:/ / www.reuters.com/article/iron-gas-usa/cheap-gas-to-increase-us-direct-reduced-iron-selfsufficiency-idUSL5N0AYFSC20130129 (accessed on 25 October 2019).

45. Carlos, P.E.; Martinis, A.D.; Jorge, B.; Lizcano, C. Energiron direct reduction ironmaking-Economical, flexible, environmentally friendly. Steel Times Int. 2010, 34, 25-30. 
46. Chen, Z.; Dang, J.; Hu, X.; Yan, H. Reduction kinetics of hematite powder in hydrogen atmosphere at moderate temperatures. Metals 2018, 8, 751. [CrossRef]

47. Van Der Walt, S.; Colbert, S.C.; Varoquaux, G. The NumPy array: A structure for efficient numerical computation. Comput. Sci. Eng. 2011, 13, 22-30. [CrossRef]

48. Alhumaizi, K.; Ajbar, A.; Soliman, M. Modelling the complex interactions between reformer and reduction furnace in a midrex-based iron plant. Canad. J. Chem. Eng. 2012, 90, 1120-1141. [CrossRef]

49. Cárdenas, J.G.G.; Conejo, A.N.; Gnechi, G.G. Optimization of Energy Consumption in Electric Arc Furnaces Operated with 100\% Dri. Metal 2007, 2007, 1-7.

50. Rojas-Cardenas, J.C.; Hasanbeigi, A.; Sheinbaum-Pardo, C.; Price, L. Energy efficiency in the Mexican iron and steel industry from an international perspective. J. Clean. Prod. 2017, 158, 335-348. [CrossRef]

51. Dİlmaç, N.; Yörük, S.; Gülaboğlu, Ů.M. Investigation of Direct Reduction Mechanism of Attepe Iron Ore by Hydrogen in a Fluidized Bed. Metall. Mater. Trans. B Process Metall. Mater. Process. Sci. 2015, 46, 2278-2287. [CrossRef]

52. Pineau, A.; Kanari, N.; Gaballah, I. Kinetics of reduction of iron oxides by $\mathrm{H}_{2}$. Part II. Low temperature reduction of magnetite. Thermochim. Acta 2007, 456, 75-88. [CrossRef]

53. Teplov, O.A. Kinetics of the low-temperature hydrogen reduction of magnetite concentrates. Russian Metall. (Metally) 2012, 2012, 8-21. [CrossRef]

54. Fruehan, R.J.; Li, Y.; Brabie, L.; Kim, E.J. Final stage of reduction of iron ores by hydrogen. Scand. J. Metall. 2005, 34, 205-212. [CrossRef]

55. Guo, D.; Hu, M.; Pu, C.; Xiao, B.; Hu, Z.; Liu, S.; Wang, X.; Zhu, X. Kinetics and mechanisms of direct reduction of iron ore-biomass composite pellets with hydrogen gas. Int. J. Hydr. Energy 2015, 40, 4733-4740. [CrossRef]

56. Ranzani da Costa, A.; Wagner, D.; Patisson, F. Modelling a new, low $\mathrm{CO}_{2}$ emissions, hydrogen steelmaking process. J. Clean. Prod. 2013, 46, 27-35. [CrossRef]

57. Zuo, H.-B.; Wang, C.; Dong, J.-J.; Jiao, K.-X.; Xu, R.-S. Reduction kinetics of iron oxide pellets with $\mathrm{H}_{2}$ and CO mixtures. Int. J. Miner. Metall. Mater. 2015, 22, 688-696. [CrossRef]

58. Pérez, F.; Granger, B.E. IPython: A system for interactive scientific computing. Comput. Sci. Eng. 2007, 9, 21-29. [CrossRef]

59. McKinney, W. Data Structures for Statistical Computing in Python. In Proceedings of the 9th Python in Science Conference, Austin, TX, USA, 28 June-3 July 2010; pp. 51-56.

60. Hunter, J.D. Matplotlib: A 2D graphics environment. Comput. Sci. Eng. 2007, 9, 99-104. [CrossRef]

61. Anaconda software distribution, Computer software. 2016. Available online: https://www.anaconda.com/ (accessed on 5 January 2020).

62. Schmidt, O.; Gambhir, A.; Staffell, I.; Hawkes, A.; Nelson, J.; Few, S. Future cost and performance of water electrolysis: An expert elicitation study. Int. J. Hydr. Energy 2017, 42, 30470-30492. [CrossRef]

63. Hydrogen, N. Nel ASA: Receives 4.5 MW Electrolyzer Purchase Order for Fossil Free Steel Production. 2019. Available online: https:/ / nelhydrogen.com/press-release/nel-asa-receives-4-5-mw-electrolyzer-purchaseorder-for-fossil-free-steel-production/ (accessed on 12 November 2019).

64. Thyssenkrupp. Hydrogen from Large-Scale Electrolysis-Efficienct Solutions for Sustainable Chemicals and Energy Storage. Available online: https://d13qmi8c46i38w.cloudfront.net/ media/UCPthyssenkruppBAISUhdeChlorineEngineers / assets.files/products / water__\}electrolysis / thyssenkrupp\{_\}electrolytic\{_\}hydrogen\{_\}brochure.pdf (accessed on 5 January 2020).

65. Santos Diogo, M.F.; Sequeira Cesar, A.C.; Figueiredo, J.L. Hydrogen production by alkaline water electrolysis. Quim. Nova Rev. 2013, 36, 1176-1193. [CrossRef]

66. Rashid, M.M.; Mesfer, M.K.A.; Naseem, H.; Danish, M. Hydrogen Production by Water Electrolysis: A Review of Alkaline Water Electrolysis, PEM Water Electrolysis and High Temperature Water Electrolysis. Int. J. Eng. Adv. Technol. 2015, 4, 2249-8958.

67. Zeng, K.; Zhang, D. Recent progress in alkaline water electrolysis for hydrogen production and applications. Progress Energy Combust. Sci. 2010, 36, 307-326. [CrossRef]

68. Zare, A.; Khanipour, M.; Sarverstani, H.K.; Kakavandi, I.A.; Shokroo, E.J.; Farniaei, M.; Baghbani, M. Hydrogen and carbon dioxide recovery from the petrochemical flare gas to methanol production using adsorption and absorption combined high-efficient method. Appl. Petrochem. Res. 2019, 9, 127-145. [CrossRef] 
69. Grande, C.A. Advances in Pressure Swing Adsorption for Gas Separation. ISRN Chem. Eng. 2012, 2012, 1-13. [CrossRef]

70. Song, C.; Liu, Q.; Ji, N.; Kansha, Y.; Tsutsumi, A. Optimization of steam methane reforming coupled with pressure swing adsorption hydrogen production process by heat integration. Appl. Energy 2015, 154, 392-401. [CrossRef]

71. Mondal, M.; Datta, A. Energy transfer in hydrogen separation from syngas using pressure swing adsorption (PSA) process: A thermodynamic model. Int. J. Energy Res. 2017, 41, 448-458. [CrossRef]

72. Mantzos, L.; Wiesenthal, T.; Matei, N.A.; Tchung-Ming, S.; Rozsai, M.; Russ, H.P.; Soria Ramirez, A. JRC-IDEES: Integrated Database of the European Energy Sector: Methodological Note; Technical report; Joint Research Council, European Union: Luxemburg, 2017. [CrossRef]

73. Hamby, D.M. A review of techniques for parameter sensitivity analysis of environmental models. Environ. Monit. Assess. 1994, 32, 135-154. [CrossRef] [PubMed]

74. Pfeifer, H.; Kirschen, M. Thermodynamic analysis of EAF energy efficiency and comparison with a statical model of electric energy model of demand. Engineering 2003, 2003, 1-16.

(C) 2020 by the authors. Licensee MDPI, Basel, Switzerland. This article is an open access article distributed under the terms and conditions of the Creative Commons Attribution (CC BY) license (http:/ / creativecommons.org/licenses/by/4.0/). 